\title{
Role of Signaling Pathways and Epigenetic Factors in Lineage Determination During Human Embryonic Stem Cell Differentiation
}

\author{
Prasenjit Sarkar and Balaji M. Rao \\ Department of Chemical and Biomolecular Engineering, \\ North Carolina State University, Raleigh, NC, \\ USA
}

\section{Introduction}

Human embryonic stem cells (hESCs) are culture-adapted cells that were originally derived from the inner cell mass (ICM) of the blastocyst-stage embryo [1]. HESCs are pluripotent cells that can be propagated indefinitely in culture, while retaining the in vivo properties of ICM cells; they can give rise to all tissues of the three germ layers (ectoderm, mesoderm and endoderm). Due to their pluripotency, hESCs have been the subject of intense research since they were initially isolated in 1998. HESCs can serve as model systems to study early human development, in addition to providing a potentially unlimited source of functional tissues for use in drug evaluation and regenerative medicine. Nevertheless, despite major advances, the exact molecular mechanisms that govern the self-renewal and differentiation of hESCs remain unclear. Indeed, a mechanistic understanding of the molecular processes regulating hESC fate can elucidate early events in human development and enable the development of protocols for efficient generation of functional tissues. Here we review the molecular mechanisms that regulate hESC fate; specifically, we focus on the role of signaling pathways and factors regulating epigenetic changes, in hESC self-renewal and lineage-specific differentiation.

In hESCs, as in embryos, differentiation is triggered by developmental cues such as morphogens or cytokines that are present in the extracellular space. These morphogens or cytokines bind to their cognate plasma membrane-bound receptors and activate specific signaling pathways inside the cell. Activation of signaling pathways involves a sequence of phosphorylation events that eventually result in the regulation of specific transcription factors. These transcription factors, in turn, can recruit other co-factors and directly cause transcription of downstream genes. Furthermore, transcription factors can recruit histone modifying and chromatin remodeling enzymes to reshuffle the epigenetic structure, such that pluripotency genes become inaccessible for transcription and are repressed, whereas lineage-specific genes become accessible and are activated. This sequence of events finally leads to expression of lineage-specific proteins such as transcription factors and structural proteins, causing a morphological change in the cell. Also, pluripotency associated transcription factors and other pluripotency-associated genes are permanently repressed, thereby completing the process of differentiation. Thus, the process of differentiation is a 
rather complex cascade of events, controlled by signaling pathways, transcription factors, epigenetic factors and lineage-specific proteins. While significant understanding of each of these functional groups (i.e., signaling pathways, transcription factors, epigenetic factors and lineage-specific proteins) has been gathered in isolation, very little is known about the interactions amongst these groups, particularly in the context of hESC differentiation. In part, interactions amongst these groups confer lineage specificity to the process of differentiation and mediate the development of specific tissues upon exposure of hESCs to certain morphogens. In this review, we focus on the role of signaling pathways, transcription factors and epigenetic factors in the context of lineage-specific differentiation of hESCs and summarize the various links between these groups. Our goal is to present a mechanistic overview of the sequence of molecular events that regulate the differentiation of hESCs along various lineages.

\section{The signaling pathways}

As briefly described earlier, the self-renewal and differentiation of hESCs is governed by several developmental cues. The most well known among these are cytokines that trigger specific signaling pathways. These extracellular ligands initiate signaling through interactions with ligand-specific cell surface receptors. Receptor-binding typically results in association of multiple receptor subunits and activation of the kinase domains of receptors or other receptor-bound effector proteins. This triggers a sequence of phosphorylation events involving various other proteins, finally resulting in the activation or inhibition of transcription factors. These transcription factors in turn are directly responsible for activating or repressing their target genes. Thus, a group of signaling pathways is usually responsible for modulating gene expression in hESCs, leading to control of the transcriptome, the proteome and ultimately cellular physiology. In this section, we summarize key signaling pathways that have been implicated in the maintenance of undifferentiated hESCs and their lineage-specific differentiation.

\subsubsection{The transforming growth factor- $\beta$ pathway}

The transforming growth factor $\beta$ (TGF- $\beta$ ) pathway is well known for its involvement in embryonic development and patterning, as well as in epithelial-to-mesenchymal transformations and carcinogenesis [2-3]. This pathway (extensively reviewed elsewhere [2, 4-5]) is divided into two branches: the Activin/Nodal branch and the Bone Morphogenetic Protein (BMP) branch. The Activin/Nodal pathway is activated by ligands such as Activin, Nodal and TGF $\beta 1$. These ligands bind to their Type II receptor, which then recruits the Type I receptor. The Type II receptor phosphorylates the intracellular domain of the Type I receptor, creating a binding site for SMAD2 and SMAD3 transcription factors. Upon binding, SMAD2/3 is phosphorylated by the Type I receptor, leading to subsequent dissociation of SMAD2/3. Phosphorylated SMAD2/3 then associates with SMAD4 and can enter the nucleus to modulate gene expression. The BMP branch is activated by the BMP ligands; binding of BMP ligands results in phosphorylation of the type I receptor by the type II receptor, and subsequent intracellular binding and phosphorylation of SMAD1/5/8. Phosphorylated SMAD1/5/8 forms a complex with SMAD4 and subsequently enters the nucleus. Unlike ligands in the Activin/Nodal branch, the BMPs have high affinities for the type I receptor and bind weakly to the type II receptor; Activin/Nodal bind with high 
affinity to their type II receptors and do not directly interact with their type I receptors. Numerous other proteins can modulate the localization and activity of SMADs (reviewed in [6-8]). Additionally, the activated TGF $\beta$ pathway receptors can also activate the Mitogen Activated Protein Kinase (MAPK) Pathway [9].

\subsubsection{Role in lineage determination}

The TGF $\beta$ pathway plays a significant role during embryogenesis across many species including flies, fishes, amphibians and mammals (reviewed in [10]). Specifically among vertebrates, Nodal is expressed throughout the epiblast [11] and is required for specification of mesoderm and endoderm from the epiblast [12]. Low levels of Nodal lead to mesoderm formation whereas high levels lead to endoderm formation [13]. Absence of Nodal signaling through active inhibition leads to ectoderm formation [12, 14]. Within the ectoderm, high levels of BMP cause formation of epidermis while low levels cause neural plate formation [15]. Intermediate levels of BMP lead to neural crest formation at the borders of the neural plate, although this a necessary but not a sufficient condition [16].

Not surprisingly, in vitro protocols for differentiating hESCs resemble in vivo conditions present during embryogenesis. Specifically, Activin causes endoderm differentiation from hESC cultures, while Activin and BMP simultaneously lead to mesoderm formation [17-21]. Inhibition of both Activin/Nodal and BMP causes neural differentiation [22] and this differentiation proceeds through an epiblast-like intermediate. Intriguingly, some amount of Activin/Nodal signaling is essential for hESC pluripotency; the pluripotency factor Nanog is a direct target of Smad2/3 [23-25] and inhibition of Activin/Nodal causes upregulation of BMP and subsequent trophectoderm differentiation [26]. Short term BMP treatment causes mesoderm formation [27] whereas long term BMP treatment leads to trophectoderm formation [28]. The disparity of BMP treatment leading to trophectoderm differentiation and not epidermal differentiation, as during embryogenesis, can in part be attributed to the fact that hESCs are derived from ICM cells and not epiblast cells. Thus, even though in vivo embryogenesis serves to provide guidelines for carrying out in vitro differentiation of hESCs, major challenges still remain. The biggest of these challenges is perhaps the heterogeneity in lineages of differentiated cells obtained through most in vitro protocols. This is primarily because most differentiation protocols rely on embryoid body (EB) formation which results in a heterogeneous environment for cells within the EB, and leads to heterogeneity in the lineages obtained after differentiation. Another challenge is the inability to form an absolute mechanistic link between the culture conditions used to differentiate hESCs, and the differentiation behavior seen in hESCs. This is mostly because the composition of serum, B27, serum replacer, conditioned medium and other components of media used for differentiation studies, are unknown [29].

\subsubsection{The Fibroblast Growth Factor pathway}

The Fibroblast Growth Factor (FGF) pathway is also known for its involvement in embryonic development and patterning, as well as in regulation of cell growth, proliferation and motility (extensively reviewed in [30-34]). The FGF pathway is activated when the FGF ligands, which have a strong affinity for Heparan Sulfate Proteoglycans (HSPGs), bind to FGF Receptors (FGFRs) forming a 2:2:2 combination of FGF: FGFR: HSPG on the cell surface. The ensuing receptor dimerization causes transphosphorylation of tyrosine residues in the intracellular domains of FGFRs through their tyrosine kinase domains. The 
phosphorylated tyrosines of FGFRs cause recruitment of the GRB2/SOS complex and its subsequent activation. SOS then activates RAS, which triggers the MAPK cascade, finally leading to the activation of extracellular-signal related kinases (ERKs). Activated Erk1/2 can phosphorylate and control the activity of a wide range of proteins [35]. Notably, Erk1/2 can phosphorylate the linker region of SMAD1 and inhibit BMP signaling [36-37]. Additionally, activated FGF receptors can also recruit FRS2/GRB2 and activate them, leading to recruitment of GAB1. GAB1 activates the Phosphatidylinositol 3-kinase (PI3K) pathway. Thus, FGF can also activate the PI3K pathway in a cell-specific context.

\subsubsection{Role in lineage determination}

The FGF pathway is needed for proper embryonic development in vertebrates. Experiments in mice have shown that FGF4 is required for ICM proliferation and maintenance [38-39], and for trophectoderm and primitive endoderm development [40]. FGF4 is secreted by the ICM and supports trophectoderm maintenance [41]. Interestingly, activation of HRas1 which is a component of the MAPK pathway, in mouse embryonic stem cells (mESCs) caused upregulation of $\mathrm{Cdx} 2$, a trophectoderm marker, and trophectoderm stem cells were derived from these mutants [42]. FGF4 secreted by ICM also causes primitive endoderm differentiation [43]. Further along the developmental timeline, FGF signaling is required for the induction of paraxial mesoderm and for maintenance (but not induction) of axial mesoderm [44-46]. FGF is required for primitive streak formation and cell migration during gastrulation [45, 47]. Inhibition of FGF is required for blood development [48-50], whereas activation of FGF signaling is required for neural differentiation [51]. However the mechanism by which FGF aids in embryonic neural differentiation is not fully understood [52-53]. In vitro studies have mimicked the role of FGF signaling in hESC maintenance and differentiation. FGF2 is required for maintaining hESCs in a pluripotent state [24, 54-55]. FGF signaling is also required for maintenance of mouse trophectoderm stem cells which are derived from the trophectoderm tissue of mouse embryos [56]. While there are no specific studies which delineate the inductive and maintenance/proliferative roles of FGF during hESC differentiation, work with mESCs have given ambiguous results, some showing that autocrine FGF2 is essential for neural differentiation [57] while others showing that FGF2 has a role in maintenance rather than induction of neural differentiation [58-59]. However, FGF signaling does seem to be necessary for inducing the posterior nervous system in vertebrate embryos $[53,60]$.

\subsubsection{The Wnt pathway}

The Wnt pathway is widely implicated during various stages of embryonic development, homeostasis as well as in cancer. This pathway (reviewed in [61-62]) has canonical and noncanonical branches. The canonical Wnt pathway is activated by binding of Wnt ligands to the Frizzled receptors and low-density lipoprotein receptor-related protein 5/6 (LRP5/6) coreceptors leading to the recruitment of Dishevelled to the Frizzled receptor. This causes recruitment of Axin to the receptor complex, causing the subsequent deactivation of Axin. In the absence of Wnt signaling, Axin associates with GSK3 $\beta$, adenomatous polyposis coli (APC), casein kinase 1 (CK1) and $\beta$-catenin. CK1 and GSK3 $\beta$ phosphorylate $\beta$-catenin causing it to be degraded. Upon Wnt activation, Axin is inhibited and $\beta$-catenin becomes derepressed, and subsequently enters the nucleus to function as a transcription factor. Various co-factors associate with $\beta$-catenin and control its promoter specificity, thus dictating the 
target genes activated or repressed by $\beta$-catenin [63-64]. The non-canonical Wnt pathway acts independently of $\beta$-catenin and is also required during embryogenesis. The details of this $\mathrm{Ca}^{2+}$-dependent pathway are reviewed in [62].

\subsubsection{Role in lineage determination}

The canonical Wnt pathway is activated during gastrulation [65] and mutation of Wnt3 blocks primitive streak formation resulting in lack of mesoderm and endoderm [66] (the primitive streak-specific transcription factor Brachyury is a direct target of Wnt3a signaling [67]). Similar defects are seen in Lrp5/6 double mutants and $\beta$-catenin loss-of-function mutants [68-69]. Interestingly, expression of Cripto, a co-receptor for Nodal signaling, is missing in $\beta$-catenin loss-of-function mutants [70]. Also, $\beta$-catenin is indispensable for endoderm formation and loss of $\beta$-catenin causes definitive endoderm to change into precardiac mesoderm [71]. Although loss of Wnt signaling leads to loss of mesoderm formation, inhibition of Wnt signaling is required for a cardiac fate [65, 72], once pre-cardiac mesoderm has been induced. Remarkably, similar reports for the role of Wnt signaling have been obtained through in vitro differentiation studies in hESCs. Over-expression of $\beta$-catenin in hESC cultures lead to primitive streak formation [73]. Inputs form Activin/Nodal and BMP pathways are necessary for further lineage specification into mesoderm/endoderm. Blocking BMP signaling abolishes mesoderm and leads to endoderm formation, whereas Activin/Nodal is required for endoderm formation [73]. Wnt is required for mesoderm differentiation but must be inhibited thereafter for cardiac mesoderm formation [74].

\subsection{The Phosphatidylinositol-3Kinase pathway}

The Phosphatidylinositol-3Kinase (PI3K) pathway regulates cell survival, apoptosis and has been implicated in cancer. The pathway as well as its role in cancer is reviewed in [75-78]. It also has been, in select cases, implicated in lineage-specific hESC differentiation [79]. The pathway is activated when PI3K is phosphorylated; this can happen through binding of Insulin to the Insulin receptor or of Insulin-like growth Factor (IGF) to Insulin-like Growth Factor Receptor (IGFR), or as previously discussed, by recruitment and activation of GAB1 by FGFR. Activated PI3K phosphorylates Phosphatidylinositol (4, 5)-biphosphate to Phosphatidylinositol $(3,4,5)$-triphosphate and creates a docking site for proteins with a pleckstrin homology $(\mathrm{PH})$ domain, such as Akt. Once Akt is properly docked, it is phosphorylated and activated by protein-dependent kinase 1 (PDK1). Akt can then dissociate and activate/repress numerous proteins by phosphorylating them [80]. The PI3K pathway has not received much attention during vertebrate embryogenesis, though some recent studies have emerged to show that it is necessary for normal embryo development [81-82]. Homozygous null mutations in the p110 $\beta$ subunit of PI3K cause embryonic lethality before formation of the blastocyst [83]. Thus, in vivo studies do not implicate PI3K signaling in differentiation of cells, but rather in maintenance of cell viability [82]. It has been hypothesized that growth factors maintain PI3K signaling during embryogenesis to guard against ectopic or metastatic growth of cells, since such ectopic/metastatic cells do not receive enough growth factors and enter the default apoptotic pathway [84]. In contrast, in vitro studies with hESCs have shown some supportive role for the PI3K pathway in definitive endoderm differentiation. Inhibition of PI3K signaling enhances definitive endoderm differentiation by Activin [85]. Other conflicting reports show that PI3K signaling stabilizes $\beta$-catenin during definitive endoderm formation [73]. A major challenge in 
elucidating the possible role of this pathway during differentiation is the inability to decouple its role in cell viability. Therefore, careful studies need to be designed to assess the extent of its role in causing differentiation.

\subsection{The Hippo pathway}

So far we have focused on developmental cues in the form of morphogens, i.e. protein ligands that physically diffuse through the embryonic tissue and pattern the embryo. Another developmental cue that has recently emerged to be of significant importance during embryogenesis is cell-cell contact. An increase in cell-cell contact is sensed by the cell through the activation of the Hippo pathway (reviewed in [86-87]). The Hippo pathway is important for organ size control, tumorigenesis, epithelial-to-mesenchymal transformation and cell-cell contact inhibition. Although the molecular mechanisms of cell-cell contact sensing are not fully understood, an increase in cell-cell contact is known to ultimately lead to phosphorylation of MST1/2 kinases. They then associate with SAV1 and phosphorylate the LATS1/2 kinases. Upon phosphorylation, LATS1/2 kinases recruit MOB1 and phosphorylate YAP and TAZ, both of which are homologues with non-redundant functions $[86,88]$. Phosphorylation of TAZ and YAP leads to their association with 14-3-3 proteins and subsequent cytoplasmic retention [89-90]. YAP and TAZ act as co-factors for various transcription factors such as TEADs, RUNX, PAX3 and SMAD1/2/3/7 and modulate their nuclear localization and/or activity [91-96]. Additionally, TAZ can associate with DVL2 and inhibit its phosphorylation by CK1, thus possibly inhibiting $\beta$-catenin activation by Wnt factors [97]. Therefore, the nucleocytoplasmic shuttling of YAP and/or TAZ can lead to changes in the activity levels of associating transcription factors, leading to differentiation [93]. Indeed, low cell-cell contact at the periphery of the embryo leads to Yap activation, which in concert with Tead4, leads to trophoblast differentiation in mouse blastocysts [98]. The inner cell mass and epiblast tissues show predominantly cytoplasmic and weakly nuclear localization for Yap, Taz and phospho-Smad2 [98-99], in agreement with the fact that Taz controls Smad2 localization [93]. While cells of the mouse ICM continue to differentiate, in vitro cultures derived from ICM (i.e. mESCs) maintain high levels of Yap. Yap is downregulated during in vitro mESC differentiation and upregulated in mouse and human induced pluripotent stem (iPS) cells [100]. Ectopic Yap expression maintains mESC phenotype even under differentiation conditions. Though it remains to be seen whether downregulation of Yap/Taz is the cause of differentiation of ICM cells in vivo, experiments with hESCs show that downregulation of TAZ initiates neural differentiation [93]. Tead and Yap suppress terminal neuronal differentiation and maintain neural progenitor populations in the vertebrate neural tube [94]. Tead2 and Yap activate Pax3 expression during neural crest formation [101]. Tead1/2 and Yap also maintain the notochord which is formed from the axial mesoderm [102]. Thus the co-activators YAP and TAZ are important for the activity of many transcription factors during embryogenesis. However, further studies are needed to uncover the specific inductive/maintenance roles of these co-factors and their responsiveness to Hippo signaling in these tissues.

\subsection{Crosstalk between signaling pathways}

There is a vast amount of crosstalk between the various pathways described here, thus adding additional complexity in the regulation of downstream transcription factors [103]. As described earlier, the TGF- $\beta$ pathway can activate the MAPK pathway directly 
downstream of receptor activation [9]. Both TGF- $\beta$ and FGF pathways can activate the PI3K pathways directly at the receptor level $[9,30]$. However, the crosstalk between pathways is cell-specific, since the available pool of interacting proteins depends on the cell-type. Also, the promoter accessibility of downstream genes is dependent on cell-type. Therefore, here we restrict our discussion to crosstalk events identified specifically in hESCs. Activin/BMP signaling induces Wnt ligand expression in hESCs [74]. Also, Activin regulates FGF, Wnt and BMP pathways in hESCs [104]. Inhibition of Activin/Nodal signaling causes downregulation of Wnt3, FGF2, FGF4 and FGF8 expression [26] and upregulation of BMP signaling [26] while activation of Activin signaling causes upregulation of Wnt3 and FGF8 expression [104]. Interestingly, upregulation of Activin signaling also causes upregulation of Nodal and Lefty expression. Cerberus1, an inhibitor of Nodal signaling, is a downstream target of both Wnt and Nodal pathways in hESCs [105]. Expression of Cripto, a co-activator of Nodal signaling, is upregulated by FGF signaling in hESCs [24]. As described earlier, YAP, which is regulated by the Hippo pathway, controls the nuclear localization of Smad2 in hESCs [93]. Thus, it can be seen that hESCs exhibit considerable endogenous signaling wherein, signaling pathways not only control their own ligand expression but also the expression of ligands of other pathways.

\section{Other regulators of differentiation}

While morphogens and other developmental cues act as the environmental input to hESCs and trigger the process of differentiation, the molecular mechanisms responsible for carrying out differentiation inside the cell are complex and require many key factors. These factors are required for the following: 1) to bring about a change in gene expression which causes the cell to transition into the new lineage-specific physiology, 2) to reshuffle the epigenetic structure of the genome, and finally 3) to make the new epigenetic structure permanent, lending stability to the newly formed cellular physiology. We will now discuss these intracellular factors that mediate various aspects of the differentiation process.

\subsection{MicroRNAs}

MicroRNAs (miRNAs) have emerged as a new paradigm for regulating gene expression at the post-transcriptional level. The role of miRNAs in embryogenesis, stem cell fate and cancer is reviewed in [106-108]. Transcription factors regulate promoter regions of miRNAs, which upon synthesis can target many mRNAs and lead to downregulation of protein synthesis. MiRNAs, which upon transcription are called pri-miRNAs, fold into secondary structures with characteristic hairpin-loops. These are recognized by Drosha, which cleaves the hairpin-loop structures to generate pre-miRNAs. Pre-miRNAs are then exported to the cytoplasm and recognized by Dicer, which cleaves one of the strands and incorporates the other into the RNA-induced silencing complex (RISC). Once incorporated into RISC, the single-stranded miRNA recognizes target mRNAs (usually many different mRNA targets) through partial sequence complimentarily, and causes down-regulation of protein synthesis. It is now known that miRNAs play an important role in embryogenesis [109] and lineagedetermination, and that many lineages have their characteristic miRNA expression patterns, akin to characteristic mRNA expression patterns [110]. The role of miRNAs in embryogenesis is evident from the fact that Dicer mutant mouse embryos die during gastrulation [111], while Dicer deficient zebrafish embryos do not develop beyond day8 [109]. The role of miRNAs in embryonic stem cell pluripotency and differentiation has also 
been demonstrated recently [107]. Dicer deficient mESCs fail to differentiate in vitro as well as in vivo [112]. Over-expression of miR-302 leads to reprogramming of human hair follicle cells and human skin cancer cells to form iPS cells [113-114]. During mESC differentiation, miR-134, miR-296 and miR-470 target and downregulate the transcription factors Nanog, Sox 2 and Oct4 [115]. MiR-200c, miR-203 and miR-183 target and repress Sox2 and Klf4, both of which are involved in maintaining pluripotency in mESCs [116]. Similarly, during hESC differentiation, miR-145 targets and represses OCT4, SOX2 and KLF4 [117]. Sall4, another pluripotency-related transcription factor, is positively regulated by the ESC cell cycle regulating (ESCC) family of miRNAs and negatively regulated by the let7 family [118]. Additionally, miRNAs are also implicated during later stages of differentiation. The musclespecific miR-1 controls cardiomyocyte differentiation and proliferation in mice by targeting the Hand2 transcription factor [119]. miR-181 controls hematopoietic differentiation in mice [120] and miR-143 regulates adipocyte differentiation [121]. MiR-196 is involved in HOX gene regulation [122-124] and the miR-200 family regulates olfactory neurogenesis [125]. MiRNAs have also been implicated in skin morphogenesis [126]. Most intriguingly, transfection of muscle-specific miR-1 or brain-specific miR-124 into human HeLa cells shifts the mRNA expression profile towards that of muscle or brain cells, respectively [127].

The expression of miRNAs is regulated by transcription factors which bind promoter regions of genes harboring miRNAs; more than half of known mammalian miRNA genes are within host gene introns and are spliced after transcription [128]. For example, Activin A signaling regulates the expression of $\sim 12$ miRNAs in hESC cultures [129]. OCT4, NANOG and SOX2 occupy the promoter regions of $\sim 14$ miRNAs in hESCs [130]. Additionally, miRNAs can be regulated directly by signaling pathways. In smooth muscle cells, BMP4 or TGF- $\beta$ signaling causes increased processing of pri-miR-21 and pri-miR-199a [131] and regulates the processing of numerous other miRNAs [132]. The MAPK/ERK pathway can regulate miRNA maturation in the cytosol by controlling phosphorylation of TRBP, which functions with Dicer [133]. However, it is largely accepted that miRNAs do not trigger differentiation but rather, are required for carrying out the process of differentiation [107]. It is hypothesized that miRNAs are required to dampen the stochastic noise in mRNA transcription levels of genes during the process of differentiation. Thus, miRNAs add another layer of complexity to gene regulation during the process of differentiation, by finetuning active mRNA levels of a gene.

\subsection{Epigenetic factors}

Our discussion on signaling pathways focused on how a change in gene expression during differentiation is initiated; while miRNAs are most probably required to stabilize the mRNA levels against stochastic perturbations during differentiation. However, to provide longterm stability to the new gene expression pattern, the epigenetic structure of the genome needs to be changed. Epigenetic factors are responsible for modulating the epigenetic structure of hESCs, while it is pluripotent (reviewed in [134]) as well as while it goes through differentiation. The epigenetic structure of the genome dictates the promoter regions that would be accessible to transcription factors for initiating transcription; the heterochromatin, being densely packed, is inaccessible whereas the euchromatin is loosely packed and readily accessible. The epigenetic structure of hESCs is different from that of differentiated cells. The epigenetic structure also differs across various lineages of differentiation. Thus, epigenetic factors are involved in changing the epigenetic structure of the genome in a lineage-dependent fashion. 
Epigenetic factors comprise broadly of histone modifying enzymes and chromatin remodeling complexes. The concerted action of both is needed to bring a stable change in the epigenetic landscape. Histone modifying enzymes are enzymes that modify histones post-translationally and create an epigenetic code of various acetylations, ubiquitinations and methylations throughout the genome (the histone code hypothesis [135-136]). This code is then recognized by chromatin remodeling enzymes, which alter the higher order structure of nucleosomes by creating heterochromatin and euchromatin. By controlling the formation of heterochromatin and euchromatin, these epigenetic factors control promoter accessibility and gene expression during differentiation. Differentiation is thought to proceed through activation of lineage-specific genes and repression of pluripotency genes [137]. This requires epigenetic factors to create repressive histone modifications on pluripotency genes (which were hitherto active) and reciprocally, to create activating histone modifications on lineagespecific genes (which were hitherto repressed). Permanent modification of histones also allows for epigenetic stability of the differentiated cell, which now becomes locked in this lineage. There is also some feedback from chromatin remodeling enzymes back to histone modifying enzymes. This means that certain chromatin remodeling enzymes can recruit back specific histone modifying enzymes for changing the histone code further. This is thought to provide more robustness to this system of epigenetic modification, thus lending further stability to the differentiated phenotype.

\subsubsection{Histone Acetyltransferases}

Of the various histone modifications, acetylation and methylation are critical for regulating the chromatin structure and gene expression [138]. These histone modifications, which create the genome-wide histone code, are regulated by Histone Acetyltransferases (HATs), Histone Deacetylases (HDACs), Histone Methyltransferases (HMTs) and Histone Demethylases. Histone Acetyltransferases are further classified into five families [139-140]: the Gcn5-related HATs (GNATs); the MYST (MOZ, Ybf2/Sas3, Sas2 and Tip60)-related HATs; p300/CBP HATs; general transcription factor HATs; and nuclear hormone-related HATs. In humans, the identified GNAT-related HAT complexes are PCAF, STAGA and TFTC. All three complexes have the chromatin-binding bromodomain which targets these complexes to chromatin. The bromodomain specifically recognizes and binds acetylated histones [141-142]. In mammals, the identified MYST-related HATs are Moz, Qkf, Mof, Tip60 (homologue of yeast NuA4 [143]) and Hbo1. The TIP60 complex contains the chromatin-binding chromodomain. The chromodomain of yeast SAGA HAT complex has been shown to recognize methylated histones [144] raising the possibility that TIP60 may also be recruited to methylated histones in humans. Together with the case of the bromodomain containing complexes, this implies that HATs may be recruited to specifically tagged histones and may function in a signaling cascade to modify the epigenetic map of the genome [145]. Mof homozygous null mice lack H4K16 acetylation and arrest at blastocyst stage [146]. Homozygous null Tip60 mutant mice also die during blastocyst stage[147]. Tip60 has also been implicated in pluripotency of ESCs [148]. Qkf is required for normal development of neurons of the cerebral cortex [149], whereas Moz is required for normal hematopoietic stem cell development [150-152].

\subsubsection{Histone Deacetylases}

The family of Histone Deacetylases is classified into four groups [153-155]: the Class I HDACs (yeast Rpd3-like) comprising of HDAC1/2, HDAC3 and HDAC8; the Class II 
HDACs (yeast Hda1-like) comprising of HDACs4-7, HDAC9 and HDAC10; the Class III HDACs (Sir2-like) comprising of SIRT1-7; and the Class IV HDACs (HDAC11-like) comprising of HDAC11. Of these, HDAC1 and HDAC2 have been identified in numerous complexes [156], namely: the SIN3 co-repressor complex, the nucleosome remodeling and deacetylase (NuRD) complex, the CoREST complex, the Nanog and Oct4 associated deacetylase (NODE) complex and the SHIP1 containing complex. HDACs complexes become associated with transcription factors through mediator proteins such as Sin3, NCoR, SMRT, CtBP and TLE [157]. Hdac1 and Hdac2 are important for embryonic development, especially during myogenesis, neurogenesis, haematopoiesis and epithelial cell differentiation [156]. The HDAC complexes NuRD and SIN3 are critical during different stages of embryonic development [158]. Mice embryos lacking Mbd3 or p66a, components of the NuRD complex, die during embryonic development [159-160]. Mbd3 null mice show normal segregation of trophoblast and primitive endoderm, but fail to develop embryonic ectoderm and extraembryonic ectoderm [161]. ICM cells of these embryos continue expressing Oct4 and the primitive endoderm marker Gata4 and fail to expand in number. Further, even though the primitive endoderm is present, the visceral endoderm fails to form. Analogously, the ICM cells derived from $M b d 3$ null mice did not expand ex-vivo and mESCs could not be formed [161]. Mbd3 null mESCs could initiate differentiation but could not commit to the differentiated lineages [162]. Mbd3 was also shown to suppress trophoblast commitment of mESCs [163]. P66a, however, was not required for proper blastocyst formation and implantation, and $p 66 a$ null mice died later during embryogenesis [160]. Mi-2 $\beta$, another component of the NuRD complex, is important for haematopoiesis, lymphopoiesis and skin development [164-167]. Similar to Mbd3 and p66a, Sin3a null mice embryos also die after implantation [168-169]. The ICM derived from these embryos shows severely retarded proliferation ex vivo [168]. Sin3b null embryos show defects in erythrocyte and granulocyte maturation and in skeletal development [170]. The Class III HDACs, known as Sirtuins (SirTs), are also implicated during differentiation and mammalian development [171]. SirT1 is highly expressed in ESCs and decreases during differentiation [172]. During late development, SirT2 modulates skeletal muscle and SirT1 modulates white adipose tissue differentiation [173-174]. Under oxidative stress, SirT1 causes astroglial differentiation in mouse neural progenitor cells [175]. SirtT2 controls gametogenesis in mice embryos [176].

\subsubsection{Histone Methyltransferases}

Various Histone Methyltransferases (HMTs) exist in the mammalian genome and many putative HMTs are yet to be discovered [177]. The major mammalian HMTs include Ash11, Dot1l, Ezh1-2, G9a, GLP, Mll1-5, Nsd1, Prdm1-6, Prdm8-16, PrSet7, Setd1-7, Setdb1-2, Setmar, Smyd1-5, Suv39h1-2, Suv4-20h1-2 and Whsc1/11. Their requirement during specific stages of mammalian development is comprehensively reviewed in [177]. These HMTs are associated with specific histone methylation activities on $\mathrm{H} 3$ and $\mathrm{H} 4$ histones. Although most of identified methylation marks are promiscuous and need further study, some histone methylation marks correlate well with gene activity. Transcriptionally active genes display H3K4me3 on their promoter region and H3K36me3 across the gene body, while repressed genes are enriched in $\mathrm{H} 3 \mathrm{~K} 27 \mathrm{me} 3$ over the gene body, with some amount of H3K9me3 and H4K20me3 [178-180]. H3K4 methylation, which is associated with gene activation, is induced by Mll1-5, Setd1a/b and Ash11. Therefore, these HMTs are critical during mammalian development. Mutations in Mll1 lead to embryonic lethality in mice [181-182] 
and cause aberrant regulation of Hox genes. Generation and/or expansion of hematopoietic stem cells, is abrogated in these embryos [183]. Mll2 null mice are capable of blastocyst formation and normal implantation without any lineage-specific growth abnormalities, but die later during embryonic development [184]. Very few genes are misregulated in Mll2 null mESCs, though Mll2 is needed for spermatogenesis [185]. Mll3 mutant mice show impaired differentiation towards the adipocyte lineage [186], while Mll5 mutant mice show impaired hematopoietic development [187]. H3K27 methylation, which is associated with gene repression and is important for embryonic development, is caused by the Ezh1-2 HTMs. Again, Ezh2 knockout causes early embryonic lethality in mouse embryos [188]. These embryos fail to complete gastrulation. Ezh2 is also shown to regulate epidermal and hematopoietic differentiation during embryogenesis [189-191]. H3K9 methylation is also associated with gene repression, and is induced by G9a, GLP, Prdm2, Setdb1 and Suv39h12. No gene targets for the Suv39h enzymes have been discovered though Suv39h double mutant mice display impaired viability as well as sterility [192]. In contrast, Setdb1 knockout causes early embryonic lethality in mouse embryos due to aberrant blastocyst formation, and mESCs cannot be derived from these mutant blastocysts [193]. Setdb1 also controls the switch between osteoblastogenesis and adipogenesis from bone marrow mesenchymal progenitor cells [194]. Similar to Setdb1, both G9a and GLP null mice also show embryonic lethality, including aberrant somitogenesis and aberrant neural tube formation [195-196]. G9a inactivates $~ 120$ genes during mESC differentiation including Oct4 and Nanog, in concert with DNA Methyltransferases Dnmt3a/b [197-198]. G9a is also implicated for genomic imprinting in the mouse placenta [199].

\subsubsection{Histone Demethylases}

In humans, the identified histone demethylases include the KDM (Lysine (K) Demethylase) families of demethylases (KDM1-6), the PHF family and the JMJD6 family (reviewed in [200201]). As with histone methyltransferases, histone demethylases are critical for embryonic development. The KDM1 family comprises of KDM1A and KDM1B. Homozygous deletion mutants of $K d m 1 a$ are early embryonic lethal and do not gastrulate [202]. Kdm1a null ES cells are pluripotent but do not form embryoid bodies and do not differentiate [202]. Kdm1b mutant mice embryos are maternal embryonic lethal and defective in imprinting [203]. The KDM2 family comprises of KDM2A and KDM2B, of which, KDM2B is implicated in osteogenesis from mesenchymal stem cells [204]. The KDM3 family consists of KDM3A, KDM3B and JMJD1C. KDM3A is required for spermatogenesis [205-206]. KDM3A is positively regulated by Oct4 and depletion of KDM3A from ES cells leads to differentiation [207]. The KDM4 family consists of KDM4A, KDM4B, KDM4C and KDM4D, of which, KDM4C is also positively regulated by Oct4 [207]. Depletion of KDM4C causes differentiation in ES cells and KDM4C also positively regulates Nanog expression [207]. The KDM5 family comprises of KDM5A, KDM5B, KDM5C and KDM5D, of which, KDM5A has been implicated in differentiation [208]. The KDM6 family consists of KDM6A, UTY and KDM6B. KDM6A and KDM6B are shown to regulate HOX gene expression during development [209-210]. KDM6B also controls neuronal differentiation and epidermal differentiation [211-213]. The PHF family includes JHDM1D, PHF2 and PHF8, while the JMJD6 family includes only JMJD6. JHDM1D is required for neural differentiation in mESCs and knockdown of $J h d m 1 d$ blocks neural differentiation [214]. 


\subsubsection{DNA Methyltransferases}

The DNA Methyltransferases (DNMTs) in humans include DNMT1, DNMT2 and DNMT3 (reviewed in [215-216]). The identified isoforms of DNMT1 are DNMT1s, DNMT1o, DNMT1b and DNMT $\triangle$ E3-6. Members of DNMT3 are DNMT3a, DNMT3b and DNMT3L, of which, DNMT3a has isoforms DNMT3a1-4 and DNMT3b has isoforms DNMT3b1-8. Dnmt1 null mice embryos die after gastrulation, before the 8-somite stage [217]. Double homozygous null mutations in Dnmt3a and Dnmt3b in mice embryos also caused similar phenotypes, with defects in neural tube closure and embryonic lethality at presomite stage [218-219]. During normal development, Dnmt3b is expressed in ICM, epiblast, embryonic ectoderm and spermatogonia of mouse embryo, whereas Dnmt3a is expressed throughout the embryo after E10.5 [220-221]. Dnmt3b is also expressed in progenitor population during hematopoiesis, spermatogenesis and neurogenesis [222]. During terminal neuronal differentiation, expression shifts to Dnmt3a [222]. Dnmt31 is required for genomic imprinting and female homozygous Dnmt3l null mice die during embryogenesis due to imprinting defects [223]. These mice show reduced spongiotrophoblast differentiation and excess trophoblast giant cell formation. Male homozygous Dnmt3l null mouse embryos show impaired spermatogenesis, but are viable [224]. Dnmt3a is also required for imprinting and spermatogenesis [225-226]. Curiously, triple homozygous knockout of Dnmt1, Dnmt3a and Dnmt3b causes no change in ESC self-renewal [227]. However, Dnmt1 null ESCs with extremely low CpG methylation levels do not differentiate [228]. Similar blockage of differentiation is also observed in dual Dnmt3a/Dnmt3b homozygous null mutants [228].

\subsubsection{Chromatin remodeling enzymes}

Chromatin remodeling enzymes are involved in controlling the higher order structure of chromatin by creating heterochromatin and euchromatin, and utilize the energy of ATP to do so. Chromatin remodeling enzymes thereby control cell fate during differentiation of ESCs (reviewed in [229]). During in vivo development, chromatin remodeling enzymes have been shown to be important for myeloid differentiation, erythropoiesis, T-cell development, adipogenesis, neurogenesis and myogenesis (reviewed in [230]). Mammalian chromatin modeling enzymes are categorized into three families: SWI/SNF, ISWI and CHD. The SWI/SNF family is characterized by the presence of either Brg1 or Brm as the catalytic subunit, and is further categorized into two subfamilies: Baf and Pbaf [231]. Brg1 homozygous null mice die at peri-implantation stage and their ICM as well as trophoblast tissues die [232]. Similar phenotypes are observed homozygous mice null for Snf5, another subunit of SWI/SNF complexes [233]. However, downregulation of Baf60c causes late embryonic lethality due to defects in cardiac and skeletal muscle development [234]. Similarly, ablation of Baf180 leads to defects in heart development and placental trophectoderm development, and subsequent embryonic lethality [235] However, homozygous null mutations in Baf155 caused early embryonic lethality due to failure of ICM cells, though trophoblast giant cells were found to be normal [236]. Heterozygotes null for Baf155 showed defective brain development. In mESCs, knockdown of Brg1 leads to loss of self-renewal and impaired ability to differentiate to ectoderm and mesoderm [237]. Inactivation of Baf250b has been associated with reduced self-renewal and increased differentiation [238]. Interestingly, ablation of Baf250a caused failure of mesoderm formation in mouse embryos as well as in ESCbased embryoid body cultures [239]. However, primitive endoderm differentiation and neuronal differentiation could be established in these cells. Brg1, Baf47, Baf155 and Baf57 are 
required to suppress Nanog expression during differentiation and knockdown of Baf155 or Baf57 lead to de-repression of Nanog levels during differentiation [240].

The ISWI family of chromatin remodelers is characterized by the presence of the Snf2h or Snf2l ATPase subunits that interact with unmodified histones. Snf2h is a part of the RSH, WICH, NoRC, CHRAC and ACF chromatin remodeling complexes. Snf2l is a part of the NURF and CERF complexes. Similar to Brg1, Snf2h homozygous null mice die at peri-implantation stage and both ICM and trophectoderm tissues degenerate [241]. Cecr2, a component of CERF, has been implicated in neural tube formation in mice [242]. Human NURF has also been implicated in neuronal development [243]. Interestingly, homozygous mice null for Bptf, a component of NURF, fail to form the visceral endoderm [244]. Bptf is required for ectoderm, mesoderm and both definitive and visceral endoderm development from ESCs in embryoid body cultures. Association between NURF complex and Smad transcription factors are necessary for endoderm formation [244]. The CHD family of chromatin remodelers is characterized by the presence of two chromodomains, with affinity for methylated histones. The CHD family is categorized into three subfamilies: family I with CHD1-2, family II with CHD3-4 and family III with CHD5-9. Downregulation of Chd1 in ESCs leads to impaired pluripotency, such that the cells are incapable of primitive endoderm and cardiac mesoderm differentiation and become prone to neural differentiation [245]. CHD3 and CHD4 are also found in NuRD histone deacetylase complexes described previously. Mutations in Chd7 are embryonic lethal, showing that Chd7 is also important for embryonic development [246].

\subsubsection{Regulation of epigenetic factors by transcription factors}

Significant literature has been accumulated concerning the regulation of epigenetic factors by transcription factors. Transcription factors lie downstream of signaling pathways, raising the possibility that signaling pathways can control the recruitment of epigenetic factors to specific promoter regions. The vast number of interactions between the Smad transcription factors and epigenetic factors is extensively reviewed in [157]. Smads 1-4 can directly interact with HATs p300 and CBP [247] while Smads 2-3 can also interact with PCAF [248]. Smads 1, 2, 3 and 5 can interact with the HAT GCN5 [249] while Smad5 can also interact with the histone methyltransferases Suv39h2 [250]. Smad7 is acetylated and protected from degradation by p300 [251]. Smads 6 and 7 can also bind and recruit HDACs [252]. As discussed before, "bridging" proteins such as NCoR, Sin3, SMRT, CtBP and TLE can also help epigenetic factors to associate with transcription factors. Smad6 can directly bind CtBP [253]. Smads 3 and 4 can interact with NCoR and Sin3 through Dach1 [254]. Smad1 can also associate with Sin3a through Dach1 [255]. Smads 2, 3 and 4 can recruit NCoR as well as Sin3/HDAC through Ski [256-257]. Smad3 can associate with Hdac1 through TGIF2 [258]. Similarly, the transcription factor $\beta$-catenin can recruit epigenetic factors and influence the epigenetic state of cells (reviewed in [64]). $\beta$-catenin can associate with the HATs p300 and CBP [259-260] as well as TIP60 [261]. $\beta$-catenin can also associate with the chromatin remodeling factors Brg1 and ISWI [64]. Additionally, $\beta$-catenin can interact with the histone methyltransferases Mll1/Mll2 [261]. The Erk kinase, which is downstream of the MAPK pathway, can phosphorylate CBP [262], Smads 1-4 [263-265] as well as Brg1 and Brm [266]. Similarly, the Akt kinase, which is downstream of PI3K signaling, can associate with SWI/SNF components Ini1, Baf155 and Baf170, and can phosphorylate Baf155 [267]. Akt can interact with the histone methyltransferases Setdb1 [268] and Ezh2 and can phosphorylate and inhibit Ezh2 [269]. Akt can also phosphorylate and activate p300 [270]. Interestingly, the pluripotency factor Oct 4 has also been shown to associate with numerous epigenetic factors 
including components of the NuRD HDAC complex (Chd4, p66a, p66 $\beta$, Mbd3, Mta1-3 and Hdac1), chromatin remodeling proteins (Brg1, Baf155 and ISWI) and DNA methyltransferases (Dnmt3a and Dnmt31) [271].

\subsection{Cell polarity}

Cell polarity is a feature of cellular physiology exhibited by epithelial cells. It refers to uneven spatial distribution of proteins across the cell, causing different parts of the cell to have different morphology and functions. Cell polarity can be classified as apical-basal polarity (epithelial cells), anterior-posterior polarity (neurons) and planar polarity (cochlea). In mammals, the apical-basal polarity of epithelial cells is regulated by three distinct protein complexes: the Crumbs/PALS1/PATJ complex, the Par3/Par6/aPKC complex and the Scribble/Dlg/Lgl complex. A detailed review of these complexes and their function in controlling epithelial architecture, cell migration and tumorigenesis can be found in [272]. The apical-basal polarity is lost during epithelial-to-mesenchymal transformation (EMT), a process that changes epithelial cells to mesenchymal cells with no apical-basal polarity and occurs during embryogenesis, fibrosis and cancer metastasis. Importantly, recent findings have indicated that epithelial cell polarity is required for early mouse embryogenesis and may be the driving factor for differentiation of certain early lineages. For example, the cell polarity regulator Par6 is required for proper trophectoderm formation in mouse embryos [273]. Downregulation of Par3 or aPKC drives blastomeres towards ICM instead of trophectoderm [274]. Interestingly, the Crumbs polarity complex has been found to interact with components of the Hippo signaling pathway [99], and the Hippo has been implicated in trophectoderm formation as discussed in the review. It will therefore be interesting to study whether cell polarity proteins indeed control trophectoderm differentiation during early stages of embryogenesis.

\section{Conclusions}

The development and morphogenesis of the embryo is under strict control by a rather small set of signaling pathways. However, the presence of multiple ligands and multiple receptors, numerous transcription factor-binding partners and significant crosstalk between pathways gives rise to vast complexity within this small set of signaling pathways. Further, lineagespecific differentiation is also controlled by complex regulation of various histone acetyltransferases, histone deacetylases, histone methyltransferases, histone demethylases, DNA methyltransferases and chromatin-remodeling enzymes. A detailed and molecular-level understanding of the determinants of lineage specificity of differentiation has only recently begun to emerge through studies of the signaling pathways and their downstream factors. We have summarized the signaling pathways and miRNAs associated with differentiation to various lineages in Table 1. Along similar lines, various histone modifying proteins and chromatin remodeling proteins associated with various lineages are summarized in Table 2. Even though these tables present a concise mechanistic linkage between various regulators of ESC differentiation, questions regarding how lineage-specific transcription factors are regulated and how a balance between opposing factors, such as HATs and HDACs, or HMTs and histone demethylases, is achieved in the cell remain largely unanswered. Further, the possible role of lineage-specific transcription factors in the recruitment of epigenetic factors also remains largely unknown. Thus, our understanding of the lineage-specificity of differentiation is still rudimentary and requires significant additional research. 


\begin{tabular}{|c|c|c|}
\hline Lineage & Signaling Pathways & $\begin{array}{l}\text { Link with Lineage-specific } \\
\text { Transcription Factors }\end{array}$ \\
\hline HESC & $\begin{array}{l}\text { Activin/Nodal [23-24] } \\
\text { FGF }[24,38-39,54-55]\end{array}$ & $\begin{array}{l}\text { Smad2/3 activates Nanog prom } \\
\text { Nanog binds and inhibits Smad1 }\end{array}$ \\
\hline Ectoderm & Block Activin/Nodal $[12,14]$ & \\
\hline Mesoderm & $\begin{array}{l}\text { Low Activin/Nodal }[13,18-19] \\
\text { Short-term BMP [18-19, 27] } \\
\text { FGF [44-47], Wnt }[66,68-69,73]\end{array}$ & $\begin{array}{l}\text { Smad1/5/8 binds Nanog prom } \\
\text { Wnt3a activates Brachyury [67] } \\
\beta \text {-catenin regulates Cripto prom }\end{array}$ \\
\hline $\begin{array}{l}\text { Definitive } \\
\text { Endoderm }\end{array}$ & $\begin{array}{l}\text { High Activin/Nodal [13, 17, 20-21] } \\
\text { Wnt [66, 68-69, 71, 73] } \\
\text { Low PI3K }[21,85]\end{array}$ & Wnt3a activates Brachyury [67] \\
\hline Epidermis & $\begin{array}{l}\text { Block Activin/Nodal }[12,14] \\
\text { High BMP [15] }\end{array}$ & Smad $1 / 5 / 8$ binds Nanog prom \\
\hline $\begin{array}{l}\text { Neural Plate / } \\
\text { Neurogenesis }\end{array}$ & $\begin{array}{l}\text { Block Activin/Nodal }[12,14,22] \\
\text { Block BMP }[15,22] \\
\text { FGF }[51,53,57,60]\end{array}$ & \\
\hline Neural Crest & $\begin{array}{l}\text { Block Activin/Nodal }[12,14] \\
\text { Low BMP [16], FGF }[51,57] \\
\text { Hippo [101] (?) }\end{array}$ & $\begin{array}{l}\text { Smad } 1 / 5 / 8 \text { binds Nanog promo } \\
\text { [25]d2 activates Pax3 promoter [ }\end{array}$ \\
\hline Trophectoderm & $\begin{array}{l}\text { Block Activin/Nodal [26] } \\
\text { Long-term BMP[27-28] } \\
\text { FGF }[40-42,56], \text { Hippo [98] }\end{array}$ & $\begin{array}{l}\text { Smad1/5/8 binds Nanog prom } \\
\text { Ras/MAPK upregulates Cdx2 } \\
\text { Yap and Tead } 4 \text { coactivate } C d x 2\end{array}$ \\
\hline $\begin{array}{l}\text { Primitive } \\
\text { Endoderm }\end{array}$ & FGF $[40,43]$ & \\
\hline $\begin{array}{l}\text { Hematopoietic } \\
\text { Mesoderm }\end{array}$ & FGF [48-49] & FGF controls Runx1, Lmo2, Scl [ \\
\hline $\begin{array}{l}\text { Cardiac } \\
\text { Mesoderm }\end{array}$ & Block Wnt [74] & \\
\hline $\begin{array}{l}\text { Adipocytic } \\
\text { Mesoderm }\end{array}$ & & \\
\hline
\end{tabular}




\begin{tabular}{|c|c|c|c|c|c|c|c|}
\hline Z常芌 。 & & Epige & etic Factors & & & & \\
\hline 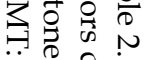 & Lineage & HAT & HDAC & HMT & HDM & DNMT & $\begin{array}{l}\text { Chromatin } \\
\text { Remodelin }\end{array}$ \\
\hline 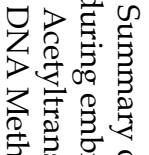 & HESC & $\begin{array}{l}\text { Tip60 } \\
{[148]}\end{array}$ & NuRD [162] & $\begin{array}{l}\text { Setdb1 } \\
{[193]}\end{array}$ & $\begin{array}{l}\text { KDM3A, } \\
\text { KDM4C [207] }\end{array}$ & & $\begin{array}{l}\text { Brg1 [232] } \\
\text { Baf155 [236 } \\
\text { Baf250b [23 } \\
\text { Snf2h [241] } \\
\end{array}$ \\
\hline 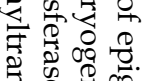 & Ectoderm & & NuRD [161] & & & & $\begin{array}{l}\text { Brg1 [237] } \\
\text { NURF [244 }\end{array}$ \\
\hline 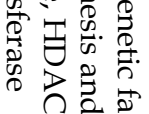 & Mesoderm & & & & & & \begin{tabular}{|l} 
Brg1 [237] \\
Baf250a [23 \\
NURF [244
\end{tabular} \\
\hline 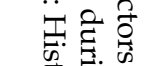 & \begin{tabular}{|l} 
Definitive \\
Endoderm
\end{tabular} & & & & & & NURF [244 \\
\hline 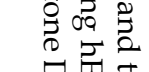 & Gametes & & SirT2 [176] & Mll2 [185] & $\begin{array}{l}\text { KDM3A [205- } \\
\text { 206] }\end{array}$ & $\begin{array}{l}\text { Dnmt31 } \\
\text { [224] }\end{array}$ & \\
\hline 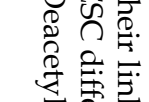 & $\begin{array}{l}\text { Neural Plate/ } \\
\text { Neurogenesis }\end{array}$ & $\begin{array}{l}\text { Qkf } \\
{[149]}\end{array}$ & $\begin{array}{l}\text { HDAC1-2 } \\
{[156], \text { SirT1 }} \\
{[175]}\end{array}$ & $\begin{array}{l}\text { G9a, GLP } \\
\text { [195-196] }\end{array}$ & $\begin{array}{l}\text { KDM6B [211-212] } \\
\text { JHDM1D[214] }\end{array}$ & $\begin{array}{l}\text { Dnmt3a, } \\
\text { Dnmt3b } \\
{[218-219]}\end{array}$ & $\begin{array}{l}\text { Baf155 [236 } \\
\text { Snf21 [242-2 }\end{array}$ \\
\hline 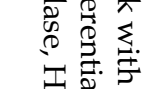 & $\begin{array}{l}\text { Trophecto- } \\
\text { derm }\end{array}$ & & NuRD [163] & & & $\begin{array}{l}\text { Dnmt31 } \\
{[223]}\end{array}$ & $\begin{array}{l}\text { Brg1 [232] } \\
\text { Baf180 [235 } \\
\text { Snf2h [241] }\end{array}$ \\
\hline 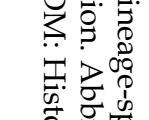 & $\begin{array}{l}\text { Hematopoietic } \\
\text { Mesoderm }\end{array}$ & $\begin{array}{l}\text { Moz } \\
{[150-} \\
152]\end{array}$ & $\begin{array}{l}\text { HDAC1-2 } \\
{[156], \text { NuRD }} \\
{[165-167]}\end{array}$ & $\begin{array}{l}\text { Mll1 [183] } \\
\text { Mll5 [187] }\end{array}$ & & & \\
\hline 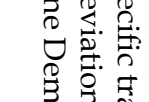 & $\begin{array}{l}\text { Cardiac } \\
\text { Mesoderm }\end{array}$ & & $\begin{array}{l}\text { HDAC1-2 } \\
{[156]}\end{array}$ & & & & $\begin{array}{l}\text { Baf60c [234 } \\
\text { Baf180 [235 } \\
\text { CHD1 [245 }\end{array}$ \\
\hline 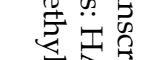 & $\begin{array}{l}\text { Adipocytic } \\
\text { Mesoderm }\end{array}$ & & SirT1 [174] & Mll3 [186] & & & \\
\hline 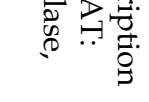 & $\begin{array}{l}\text { Myogenic } \\
\text { Mesoderm }\end{array}$ & & $\begin{array}{l}\text { HDAC1-2 } \\
{[156]} \\
\text { SirT2 [173] }\end{array}$ & & & & Baf60c [234 \\
\hline & $\begin{array}{l}\text { Primitive } \\
\text { Endoderm }\end{array}$ & & NuRD [161] & & & & CHD1 [245 \\
\hline
\end{tabular}




\section{Acknowledgments}

The authors gratefully acknowledge funding support from the National Science Foundation (NSF) Grant CBET-0966859.

\section{References}

[1] Thomson, J.A., et al., Embryonic stem cell lines derived from human blastocysts. Science, 1998. 282(5391): p. 1145-7.

[2] Gordon, K.J. and G.C. Blobe, Role of transforming growth factor-beta superfamily signaling pathways in human disease. Biochim Biophys Acta, 2008. 1782(4): p. 197-228.

[3] Blobe, G.C., W.P. Schiemann, and H.F. Lodish, Role of transforming growth factor beta in human disease. N Engl J Med, 2000. 342(18): p. 1350-8.

[4] Feng, X.H. and R. Derynck, Specificity and versatility in tgf-beta signaling through Smads. Annu Rev Cell Dev Biol, 2005. 21: p. 659-93.

[5] Shi, Y. and J. Massague, Mechanisms of TGF-beta signaling from cell membrane to the nucleus. Cell, 2003. 113(6): p. 685-700.

[6] Xu, L., Regulation of Smad activities. Biochim Biophys Acta, 2006. 1759(11-12): p. 503-13.

[7] Massague, J., J. Seoane, and D. Wotton, Smad transcription factors. Genes Dev, 2005. 19(23): p. 2783-810.

[8] Miyazawa, K., et al., Two major Smad pathways in TGF-beta superfamily signalling. Genes Cells, 2002. 7(12): p. 1191-204.

[9] Zhang, Y.E., Non-Smad pathways in TGF-beta signaling. Cell Res, 2009. 19(1): p. 128-39.

[10] Wu, M.Y. and C.S. Hill, Tgf-beta superfamily signaling in embryonic development and homeostasis. Dev Cell, 2009. 16(3): p. 329-43.

[11] Yamamoto, M., et al., Nodal antagonists regulate formation of the anteroposterior axis of the mouse embryo. Nature, 2004. 428(6981): p. 387-92.

[12] Schier, A.F., Nodal signaling in vertebrate development. Annu Rev Cell Dev Biol, 2003. 19: p. 589-621.

[13] Zorn, A.M. and J.M. Wells, Molecular basis of vertebrate endoderm development. Int Rev Cytol, 2007. 259: p. 49-111.

[14] Zhang, J., et al., The role of maternal VegT in establishing the primary germ layers in Xenopus embryos. Cell, 1998. 94(4): p. 515-24.

[15] Wilson, P.A., et al., Concentration-dependent patterning of the Xenopus ectoderm by BMP4 and its signal transducer Smad1. Development, 1997. 124(16): p. 3177-84.

[16] Sauka-Spengler, T. and M. Bronner-Fraser, A gene regulatory network orchestrates neural crest formation. Nat Rev Mol Cell Biol, 2008. 9(7): p. 557-68.

[17] D'Amour, K.A., et al., Production of pancreatic hormone-expressing endocrine cells from human embryonic stem cells. Nat Biotechnol, 2006. 24(11): p. 1392-401.

[18] Yao, S., et al., Long-term self-renewal and directed differentiation of human embryonic stem cells in chemically defined conditions. Proc Natl Acad Sci U S A, 2006. 103(18): p. 690712.

[19] Schuldiner, M., et al., Effects of eight growth factors on the differentiation of cells derived from human embryonic stem cells. Proc Natl Acad Sci U S A, 2000. 97(21): p. 11307-12.

[20] Kroon, E., et al., Pancreatic endoderm derived from human embryonic stem cells generates glucose-responsive insulin-secreting cells in vivo. Nat Biotechnol, 2008. 26(4): p. 443-52. 
[21] D'Amour, K.A., et al., Efficient differentiation of human embryonic stem cells to definitive endoderm. Nat Biotechnol, 2005. 23(12): p. 1534-41.

[22] Chambers, S.M., et al., Highly efficient neural conversion of human ES and iPS cells by dual inhibition of SMAD signaling. Nat Biotechnol, 2009. 27(3): p. 275-80.

[23] James, D., et al., TGFbeta/activin/nodal signaling is necessary for the maintenance of pluripotency in human embryonic stem cells. Development, 2005. 132(6): p. 1273-82.

[24] Vallier, L., M. Alexander, and R.A. Pedersen, Activin/Nodal and FGF pathways cooperate to maintain pluripotency of human embryonic stem cells. J Cell Sci, 2005. 118(Pt 19): p. 4495-509.

[25] Xu, R.H., et al., NANOG is a direct target of TGFbeta/activin-mediated SMAD signaling in human ESCs. Cell Stem Cell, 2008. 3(2): p. 196-206.

[26] Wu, Z., et al., Combinatorial signals of activin/nodal and bone morphogenic protein regulate the early lineage segregation of human embryonic stem cells. J Biol Chem, 2008. 283(36): p. 24991-5002.

[27] Zhang, P., et al., Short-term BMP-4 treatment initiates mesoderm induction in human embryonic stem cells. Blood, 2008. 111(4): p. 1933-41.

[28] Xu, R.H., et al., BMP4 initiates human embryonic stem cell differentiation to trophoblast. Nat Biotechnol, 2002. 20(12): p. 1261-4.

[29] Suter, D.M. and K.H. Krause, Neural commitment of embryonic stem cells: molecules, pathways and potential for cell therapy. J Pathol, 2008. 215(4): p. 355-68.

[30] Villegas, S.N., M. Canham, and J.M. Brickman, FGF signalling as a mediator of lineage transitions--evidence from embryonic stem cell differentiation. J Cell Biochem, 2010. 110(1): p. 10-20.

[31] Dorey, K. and E. Amaya, FGF signalling: diverse roles during early vertebrate embryogenesis. Development, 2010. 137(22): p. 3731-42.

[32] Lanner, F. and J. Rossant, The role of FGF/Erk signaling in pluripotent cells. Development, 2010. 137(20): p. 3351-60.

[33] Kosaka, N., et al., Pleiotropic function of FGF-4: its role in development and stem cells. Dev Dyn, 2009. 238(2): p. 265-76.

[34] Ramos, J.W., The regulation of extracellular signal-regulated kinase (ERK) in mammalian cells. Int J Biochem Cell Biol, 2008. 40(12): p. 2707-19.

[35] Yoon, S. and R. Seger, The extracellular signal-regulated kinase: multiple substrates regulate diverse cellular functions. Growth Factors, 2006. 24(1): p. 21-44.

[36] Eivers, E., L.C. Fuentealba, and E.M. De Robertis, Integrating positional information at the level of Smad1/5/8. Curr Opin Genet Dev, 2008. 18(4): p. 304-10.

[37] Pera, E.M., et al., Integration of IGF, FGF, and anti-BMP signals via Smad1 phosphorylation in neural induction. Genes Dev, 2003. 17(24): p. 3023-8.

[38] Feldman, B., et al., Requirement of FGF-4 for postimplantation mouse development. Science, 1995. 267(5195): p. 246-9.

[39] Arman, E., et al., Targeted disruption of fibroblast growth factor (FGF) receptor 2 suggests a role for FGF signaling in pregastrulation mammalian development. Proc Natl Acad Sci U S A, 1998. 95(9): p. 5082-7.

[40] Goldin, S.N. and V.E. Papaioannou, Paracrine action of FGF4 during periimplantation development maintains trophectoderm and primitive endoderm. Genesis, 2003. 36(1): p. 40-7. 
[41] Rappolee, D.A., et al., Expression and function of FGF-4 in peri-implantation development in mouse embryos. Development, 1994. 120(8): p. 2259-69.

[42] Lu, C.W., et al., Ras-MAPK signaling promotes trophectoderm formation from embryonic stem cells and mouse embryos. Nat Genet, 2008. 40(7): p. 921-6.

[43] Yamanaka, Y., F. Lanner, and J. Rossant, FGF signal-dependent segregation of primitive endoderm and epiblast in the mouse blastocyst. Development, 2010. 137(5): p. 715-24.

[44] Fletcher, R.B. and R.M. Harland, The role of FGF signaling in the establishment and maintenance of mesodermal gene expression in Xenopus. Dev Dyn, 2008. 237(5): p. 124354.

[45] Amaya, E., T.J. Musci, and M.W. Kirschner, Expression of a dominant negative mutant of the FGF receptor disrupts mesoderm formation in Xenopus embryos. Cell, 1991. 66(2): p. 257-70.

[46] Amaya, E., et al., FGF signalling in the early specification of mesoderm in Xenopus. Development, 1993. 118(2): p. 477-87.

[47] Ciruna, B. and J. Rossant, FGF signaling regulates mesoderm cell fate specification and morphogenetic movement at the primitive streak. Dev Cell, 2001. 1(1): p. 37-49.

[48] Isaacs, H.V., A.E. Deconinck, and M.E. Pownall, FGF4 regulates blood and muscle specification in Xenopus laevis. Biol Cell, 2007. 99(3): p. 165-73.

[49] Kumano, G. and W.C. Smith, FGF signaling restricts the primary blood islands to ventral mesoderm. Dev Biol, 2000. 228(2): p. 304-14.

[50] Walmsley, M., D. Cleaver, and R. Patient, Fibroblast growth factor controls the timing of Scl, Lmo2, and Runx1 expression during embryonic blood development. Blood, 2008. 111(3): p. 1157-66.

[51] Stern, C.D., Neural induction: old problem, new findings, yet more questions. Development, 2005. 132(9): p. 2007-21.

[52] Linker, C., et al., Cell communication with the neural plate is required for induction of neural markers by BMP inhibition: evidence for homeogenetic induction and implications for Xenopus animal cap and chick explant assays. Dev Biol, 2009. 327(2): p. 478-86.

[53] Wills, A.E., et al., BMP antagonists and FGF signaling contribute to different domains of the neural plate in Xenopus. Dev Biol, 2010. 337(2): p. 335-50.

[54] Chiao, E., et al., Derivation of human embryonic stem cells in standard and chemically defined conditions. Methods Cell Biol, 2008. 86: p. 1-14.

[55] Ludwig, T.E., et al., Derivation of human embryonic stem cells in defined conditions. Nat Biotechnol, 2006. 24(2): p. 185-7.

[56] Tanaka, S., et al., Promotion of trophoblast stem cell proliferation by FGF4. Science, 1998. 282(5396): p. 2072-5.

[57] Ying, Q.L., et al., Conversion of embryonic stem cells into neuroectodermal precursors in adherent monoculture. Nat Biotechnol, 2003. 21(2): p. 183-6.

[58] Smukler, S.R., et al., Embryonic stem cells assume a primitive neural stem cell fate in the absence of extrinsic influences. J Cell Biol, 2006. 172(1): p. 79-90.

[59] Holowacz, T. and S. Sokol, FGF is required for posterior neural patterning but not for neural induction. Dev Biol, 1999. 205(2): p. 296-308.

[60] Rentzsch, F., et al., Fgf signaling induces posterior neuroectoderm independently of Bmp signaling inhibition. Dev Dyn, 2004. 231(4): p. 750-7.

[61] MacDonald, B.T., K. Tamai, and X. He, Wnt/beta-catenin signaling: components, mechanisms, and diseases. Dev Cell, 2009. 17(1): p. 9-26. 
[62] Sugimura, R. and L. Li, Noncanonical Wnt signaling in vertebrate development, stem cells, and diseases. Birth Defects Res C Embryo Today, 2010. 90(4): p. 243-56.

[63] Teo, J.L. and M. Kahn, The Wnt signaling pathway in cellular proliferation and differentiation: A tale of two coactivators. Adv Drug Deliv Rev, 2010. 62(12): p. 1149-55.

[64] Mosimann, C., G. Hausmann, and K. Basler, Beta-catenin hits chromatin: regulation of Wnt target gene activation. Nat Rev Mol Cell Biol, 2009. 10(4): p. 276-86.

[65] Yamaguchi, T.P., Heads or tails: Wnts and anterior-posterior patterning. Curr Biol, 2001. 11(17): p. R713-24.

[66] Liu, P., et al., Requirement for Wnt3 in vertebrate axis formation. Nat Genet, 1999. 22(4): p. 361-5.

[67] Yamaguchi, T.P., et al., T (Brachyury) is a direct target of Wnt3a during paraxial mesoderm specification. Genes Dev, 1999. 13(24): p. 3185-90.

[68] Huelsken, J., et al., Requirement for beta-catenin in anterior-posterior axis formation in mice. J Cell Biol, 2000. 148(3): p. 567-78.

[69] Kelly, O.G., K.I. Pinson, and W.C. Skarnes, The Wht co-receptors Lrp5 and Lrp6 are essential for gastrulation in mice. Development, 2004. 131(12): p. 2803-15.

[70] Morkel, M., et al., Beta-catenin regulates Cripto- and Wnt3-dependent gene expression programs in mouse axis and mesoderm formation. Development, 2003. 130(25): p. 628394.

[71] Lickert, H., et al., Formation of multiple hearts in mice following deletion of beta-catenin in the embryonic endoderm. Dev Cell, 2002. 3(2): p. 171-81.

[72] Huelsken, J. and W. Birchmeier, New aspects of Wht signaling pathways in higher vertebrates. Curr Opin Genet Dev, 2001. 11(5): p. 547-53.

[73] Sumi, T., et al., Defining early lineage specification of human embryonic stem cells by the orchestrated balance of canonical Wnt/beta-catenin, Activin/Nodal and BMP signaling. Development, 2008. 135(17): p. 2969-79.

[74] Paige, S.L., et al., Endogenous Wnt/beta-catenin signaling is required for cardiac differentiation in human embryonic stem cells. PLoS One, 2010. 5(6): p. e11134.

[75] Cantley, L.C., The phosphoinositide 3-kinase pathway. Science, 2002. 296(5573): p. 1655-7.

[76] Engelman, J.A., Targeting PI3K signalling in cancer: opportunities, challenges and limitations. Nat Rev Cancer, 2009. 9(8): p. 550-62.

[77] Engelman, J.A., J. Luo, and L.C. Cantley, The evolution of phosphatidylinositol 3-kinases as regulators of growth and metabolism. Nat Rev Genet, 2006. 7(8): p. 606-19.

[78] Wong, K.K., J.A. Engelman, and L.C. Cantley, Targeting the PI3K signaling pathway in cancer. Curr Opin Genet Dev, 2010. 20(1): p. 87-90.

[79] Ramasamy, T.S. and W. Cui, Inhibition of phosphatidylinositol-3-kinase signalling promotes Activin A induced definitive endoderm differentiation of human embryonic stem cells. Differentiation, 2010. 80: p. S25-S25.

[80] Franke, T.F., PI3K/Akt: getting it right matters. Oncogene, 2008. 27(50): p. 6473-88.

[81] Zheng, W. and K. Liu, The emerging role of maternal phosphatidylinositol 3 kinase (PI3K) signaling in manipulating mammalian preimplantation embryogenesis. Cell Cycle, 2011. 10(2): p. 178-9.

[82] O'Neill, C., Phosphatidylinositol 3-kinase signaling in mammalian preimplantation embryo development. Reproduction, 2008. 136(2): p. 147-56.

[83] Bi, L., et al., Early embryonic lethality in mice deficient in the p110beta catalytic subunit of PI 3-kinase. Mamm Genome, 2002. 13(3): p. 169-72. 
[84] Raff, M.C., et al., Programmed cell death and the control of cell survival. Philos Trans R Soc Lond B Biol Sci, 1994. 345(1313): p. 265-8.

[85] McLean, A.B., et al., Activin a efficiently specifies definitive endoderm from human embryonic stem cells only when phosphatidylinositol 3-kinase signaling is suppressed. Stem Cells, 2007. 25(1): p. 29-38.

[86] Zeng, Q. and W. Hong, The emerging role of the hippo pathway in cell contact inhibition, organ size control, and cancer development in mammals. Cancer Cell, 2008. 13(3): p. 18892.

[87] Oh, H. and K.D. Irvine, Yorkie: the final destination of Hippo signaling. Trends Cell Biol, 2010. 20(7): p. 410-7.

[88] Lei, Q.Y., et al., TAZ promotes cell proliferation and epithelial-mesenchymal transition and is inhibited by the hippo pathway. Mol Cell Biol, 2008. 28(7): p. 2426-36.

[89] Kanai, F., et al., TAZ: a novel transcriptional co-activator regulated by interactions with 14-33 and PDZ domain proteins. EMBO J, 2000. 19(24): p. 6778-91.

[90] Oka, T. and M. Sudol, Nuclear localization and pro-apoptotic signaling of YAP2 require intact PDZ-binding motif. Genes Cells, 2009. 14(5): p. 607-15.

[91] Ferrigno, O., et al., Yes-associated protein (YAP65) interacts with Smad7 and potentiates its inhibitory activity against TGF-beta/Smad signaling. Oncogene, 2002. 21(32): p. 487984.

[92] Chan, S.W., et al., TEADs mediate nuclear retention of TAZ to promote oncogenic transformation. J Biol Chem, 2009. 284(21): p. 14347-58.

[93] Varelas, X., et al., TAZ controls Smad nucleocytoplasmic shuttling and regulates human embryonic stem-cell self-renewal. Nat Cell Biol, 2008. 10(7): p. 837-48.

[94] Cao, X., S.L. Pfaff, and F.H. Gage, YAP regulates neural progenitor cell number via the TEA domain transcription factor. Genes Dev, 2008. 22(23): p. 3320-34.

[95] Wang, K., et al., YAP, TAZ, and Yorkie: a conserved family of signal-responsive transcriptional coregulators in animal development and human disease. Biochem Cell Biol, 2009. 87(1): p. 77-91.

[96] Alarcon, C., et al., Nuclear CDKs drive Smad transcriptional activation and turnover in BMP and TGF-beta pathways. Cell, 2009. 139(4): p. 757-69.

[97] Varelas, X., et al., The Hippo pathway regulates Wnt/beta-catenin signaling. Dev Cell, 2010. 18(4): p. 579-91.

[98] Nishioka, N., et al., The Hippo signaling pathway components Lats and Yap pattern Tead4 activity to distinguish mouse trophectoderm from inner cell mass. Dev Cell, 2009. 16(3): p. 398-410.

[99] Varelas, X., et al., The Crumbs complex couples cell density sensing to Hippo-dependent control of the TGF-beta-SMAD pathway. Dev Cell, 2010. 19(6): p. 831-44.

[100] Lian, I., et al., The role of YAP transcription coactivator in regulating stem cell self-renewal and differentiation. Genes Dev, 2010. 24(11): p. 1106-18.

[101] Milewski, R.C., et al., Identification of minimal enhancer elements sufficient for Pax3 expression in neural crest and implication of Tead2 as a regulator of Pax3. Development, 2004. 131(4): p. 829-37.

[102] Sawada, A., et al., Redundant roles of Tead1 and Tead2 in notochord development and the regulation of cell proliferation and survival. Mol Cell Biol, 2008. 28(10): p. 3177-89.

[103] Guo, X. and X.F. Wang, Signaling cross-talk between TGF-beta/BMP and other pathways. Cell Res, 2009. 19(1): p. 71-88. 
[104] Xiao, L., X. Yuan, and S.J. Sharkis, Activin A maintains self-renewal and regulates fibroblast growth factor, Wnt, and bone morphogenic protein pathways in human embryonic stem cells. Stem Cells, 2006. 24(6): p. 1476-86.

[105] Katoh, M., CER1 is a common target of WNT and NODAL signaling pathways in human embryonic stem cells. Int J Mol Med, 2006. 17(5): p. 795-9.

[106] Wienholds, E. and R.H. Plasterk, MicroRNA function in animal development. FEBS Lett, 2005. 579(26): p. 5911-22.

[107] Tiscornia, G. and J.C. Izpisua Belmonte, MicroRNAs in embryonic stem cell function and fate. Genes Dev, 2010. 24(24): p. 2732-41.

[108] Navarro, A. and M. Monzo, MicroRNAs in human embryonic and cancer stem cells. Yonsei Med J, 2010. 51(5): p. 622-32.

[109] Wienholds, E., et al., The microRNA-producing enzyme Dicer1 is essential for zebrafish development. Nat Genet, 2003. 35(3): p. 217-8.

[110] Wienholds, E., et al., MicroRNA expression in zebrafish embryonic development. Science, 2005. 309(5732): p. 310-1.

[111] Bernstein, E., et al., Dicer is essential for mouse development. Nat Genet, 2003. 35(3): p. 215-7.

[112] Kanellopoulou, C., et al., Dicer-deficient mouse embryonic stem cells are defective in differentiation and centromeric silencing. Genes Dev, 2005. 19(4): p. 489-501.

[113] Lin, S.L., et al., Regulation of somatic cell reprogramming through inducible mir-302 expression. Nucleic Acids Res, 2011. 39(3): p. 1054-65.

[114] Lin, S.L., et al., Mir-302 reprograms human skin cancer cells into a pluripotent ES-cell-like state. RNA, 2008. 14(10): p. 2115-24.

[115] Tay, Y., et al., MicroRNAs to Nanog, Oct4 and Sox2 coding regions modulate embryonic stem cell differentiation. Nature, 2008. 455(7216): p. 1124-8.

[116] Wellner, U., et al., The EMT-activator ZEB1 promotes tumorigenicity by repressing stemness-inhibiting microRNAs. Nat Cell Biol, 2009. 11(12): p. 1487-95.

[117] Xu, N., et al., MicroRNA-145 regulates OCT4, SOX2, and KLF4 and represses pluripotency in human embryonic stem cells. Cell, 2009. 137(4): p. 647-58.

[118] Melton, C., R.L. Judson, and R. Blelloch, Opposing microRNA families regulate self-renewal in mouse embryonic stem cells. Nature, 2010. 463(7281): p. 621-6.

[119] Zhao, Y., E. Samal, and D. Srivastava, Serum response factor regulates a muscle-specific microRNA that targets Hand2 during cardiogenesis. Nature, 2005. 436(7048): p. 214-20.

[120] Chen, C.Z., et al., MicroRNAs modulate hematopoietic lineage differentiation. Science, 2004. 303(5654): p. 83-6.

[121] Esau, C., et al., MicroRNA-143 regulates adipocyte differentiation. J Biol Chem, 2004. 279(50): p. 52361-5.

[122] Kawasaki, H. and K. Taira, MicroRNA-196 inhibits HOXB8 expression in myeloid differentiation of HL60 cells. Nucleic Acids Symp Ser (Oxf), 2004(48): p. 211-2.

[123] Hornstein, E., et al., The microRNA miR-196 acts upstream of Hoxb8 and Shh in limb development. Nature, 2005. 438(7068): p. 671-4.

[124] Yekta, S., I.H. Shih, and D.P. Bartel, MicroRNA-directed cleavage of HOXB8 mRNA. Science, 2004. 304(5670): p. 594-6.

[125] Choi, P.S., et al., Members of the miRNA-200 family regulate olfactory neurogenesis. Neuron, 2008. 57(1): p. 41-55. 
[126] Yi, R., et al., Morphogenesis in skin is governed by discrete sets of differentially expressed microRNAs. Nat Genet, 2006. 38(3): p. 356-62.

[127] Lim, L.P., et al., Microarray analysis shows that some microRNAs downregulate large numbers of target mRNAs. Nature, 2005. 433(7027): p. 769-73.

[128] Rodriguez, A., et al., Identification of mammalian microRNA host genes and transcription units. Genome Res, 2004. 14(10A): p. 1902-10.

[129] Tsai, Z.Y., et al., Identification of microRNAs regulated by activin A in human embryonic stem cells. J Cell Biochem, 2010. 109(1): p. 93-102.

[130] Boyer, L.A., et al., Core transcriptional regulatory circuitry in human embryonic stem cells. Cell, 2005. 122(6): p. 947-56.

[131] Davis, B.N., et al., SMAD proteins control DROSHA-mediated microRNA maturation. Nature, 2008. 454(7200): p. 56-61.

[132] Davis, B.N., et al., Smad proteins bind a conserved RNA sequence to promote microRNA maturation by Drosha. Mol Cell, 2010. 39(3): p. 373-84.

[133] Paroo, Z., et al., Phosphorylation of the human microRNA-generating complex mediates MAPK/Erk signaling. Cell, 2009. 139(1): p. 112-22.

[134] Lessard, J.A. and G.R. Crabtree, Chromatin regulatory mechanisms in pluripotency. Annu Rev Cell Dev Biol, 2010. 26: p. 503-32.

[135] Turner, B.M., Histone acetylation and an epigenetic code. Bioessays, 2000. 22(9): p. 836-45.

[136] Strahl, B.D. and C.D. Allis, The language of covalent histone modifications. Nature, 2000. 403(6765): p. 41-5.

[137] Hirabayashi, Y. and Y. Gotoh, Epigenetic control of neural precursor cell fate during development. Nat Rev Neurosci, 2010. 11(6): p. 377-88.

[138] Shahbazian, M.D. and M. Grunstein, Functions of site-specific histone acetylation and deacetylation. Annu Rev Biochem, 2007. 76: p. 75-100.

[139] Carrozza, M.J., et al., The diverse functions of histone acetyltransferase complexes. Trends Genet, 2003. 19(6): p. 321-9.

[140] Lee, K.K. and J.L. Workman, Histone acetyltransferase complexes: one size doesn't fit all. Nat Rev Mol Cell Biol, 2007. 8(4): p. 284-95.

[141] Dhalluin, C., et al., Structure and ligand of a histone acetyltransferase bromodomain. Nature, 1999. 399(6735): p. 491-6.

[142] Hassan, A.H., et al., Function and selectivity of bromodomains in anchoring chromatinmodifying complexes to promoter nucleosomes. Cell, 2002. 111(3): p. 369-79.

[143] Doyon, Y., et al., Structural and functional conservation of the NuA4 histone acetyltransferase complex from yeast to humans. Mol Cell Biol, 2004. 24(5): p. 1884-96.

[144] Pray-Grant, M.G., et al., Chd1 chromodomain links histone H3 methylation with SAGA- and SLIK-dependent acetylation. Nature, 2005. 433(7024): p. 434-8.

[145] Schreiber, S.L. and B.E. Bernstein, Signaling network model of chromatin. Cell, 2002. 111(6): p. 771-8.

[146] Gupta, A., et al., The mammalian ortholog of Drosophila MOF that acetylates histone H4 lysine 16 is essential for embryogenesis and oncogenesis. Mol Cell Biol, 2008. 28(1): p. 397-409.

[147] Hu, Y., et al., Homozygous disruption of the Tip60 gene causes early embryonic lethality. Dev Dyn, 2009. 238(11): p. 2912-21.

[148] Fazzio, T.G., J.T. Huff, and B. Panning, An RNAi screen of chromatin proteins identifies Tip60-p400 as a regulator of embryonic stem cell identity. Cell, 2008. 134(1): p. 162-74. 
[149] Thomas, T., et al., Querkopf, a MYST family histone acetyltransferase, is required for normal cerebral cortex development. Development, 2000. 127(12): p. 2537-48.

[150] Perez-Campo, F.M., et al., The histone acetyl transferase activity of monocytic leukemia zinc finger is critical for the proliferation of hematopoietic precursors. Blood, 2009. 113(20): p. 4866-74.

[151] Thomas, T., et al., Monocytic leukemia zinc finger protein is essential for the development of long-term reconstituting hematopoietic stem cells. Genes Dev, 2006. 20(9): p. 1175-86.

[152] Katsumoto, T., et al., MOZ is essential for maintenance of hematopoietic stem cells. Genes Dev, 2006. 20(10): p. 1321-30.

[153] Dokmanovic, M., C. Clarke, and P.A. Marks, Histone deacetylase inhibitors: overview and perspectives. Mol Cancer Res, 2007. 5(10): p. 981-9.

[154] Gray, S.G. and T.J. Ekstrom, The human histone deacetylase family. Exp Cell Res, 2001. 262(2): p. 75-83.

[155] Khochbin, S., et al., Functional significance of histone deacetylase diversity. Curr Opin Genet Dev, 2001. 11(2): p. 162-6.

[156] Brunmeir, R., S. Lagger, and C. Seiser, Histone deacetylase HDAC1/HDAC2-controlled embryonic development and cell differentiation. Int J Dev Biol, 2009. 53(2-3): p. 275-89.

[157] van Grunsven, L.A., et al., Smads and chromatin modulation. Cytokine Growth Factor Rev, 2005. 16(4-5): p. 495-512.

[158] McDonel, P., I. Costello, and B. Hendrich, Keeping things quiet: roles of NuRD and Sin3 co-repressor complexes during mammalian development. Int J Biochem Cell Biol, 2009. 41(1): p. 108-16.

[159] Hendrich, B., et al., Closely related proteins MBD2 and MBD3 play distinctive but interacting roles in mouse development. Genes Dev, 2001. 15(6): p. 710-23.

[160] Marino, S. and R. Nusse, Mutants in the mouse NuRD/Mi2 component P66alpha are embryonic lethal. PLoS One, 2007. 2(6): p. e519.

[161] Kaji, K., J. Nichols, and B. Hendrich, Mbd3, a component of the NuRD co-repressor complex, is required for development of pluripotent cells. Development, 2007. 134(6): p. 1123-32.

[162] Kaji, K., et al., The NuRD component Mbd3 is required for pluripotency of embryonic stem cells. Nat Cell Biol, 2006. 8(3): p. 285-92.

[163] Zhu, D., et al., Mbd3, a component of NuRD/Mi-2 complex, helps maintain pluripotency of mouse embryonic stem cells by repressing trophectoderm differentiation. PLoS One, 2009. 4(11): p. e7684.

[164] Kashiwagi, M., B.A. Morgan, and K. Georgopoulos, The chromatin remodeler Mi-2beta is required for establishment of the basal epidermis and normal differentiation of its progeny. Development, 2007. 134(8): p. 1571-82.

[165] Naito, T., et al., Antagonistic interactions between Ikaros and the chromatin remodeler Mi2beta determine silencer activity and Cd4 gene expression. Immunity, 2007. 27(5): p. 72334.

[166] Williams, C.J., et al., The chromatin remodeler Mi-2beta is required for CD4 expression and $T$ cell development. Immunity, 2004. 20(6): p. 719-33.

[167] Yoshida, T., et al., The role of the chromatin remodeler Mi-2beta in hematopoietic stem cell self-renewal and multilineage differentiation. Genes Dev, 2008. 22(9): p. 1174-89.

[168] Cowley, S.M., et al., The mSin3A chromatin-modifying complex is essential for embryogenesis and T-cell development. Mol Cell Biol, 2005. 25(16): p. 6990-7004. 
[169] Dannenberg, J.H., et al., mSin3A corepressor regulates diverse transcriptional networks governing normal and neoplastic growth and survival. Genes Dev, 2005. 19(13): p. 158195.

[170] David, G., et al., Specific requirement of the chromatin modifier mSin3B in cell cycle exit and cellular differentiation. Proc Natl Acad Sci U S A, 2008. 105(11): p. 4168-72.

[171] Vaquero, A., The conserved role of sirtuins in chromatin regulation. Int J Dev Biol, 2009. 53(2-3): p. 303-22.

[172] Kuzmichev, A., et al., Composition and histone substrates of polycomb repressive group complexes change during cellular differentiation. Proc Natl Acad Sci U S A, 2005. 102(6): p. 1859-64.

[173] Fulco, M., et al., Sir2 regulates skeletal muscle differentiation as a potential sensor of the redox state. Mol Cell, 2003. 12(1): p. 51-62.

[174] Picard, F., et al., Sirt1 promotes fat mobilization in white adipocytes by repressing PPARgamma. Nature, 2004. 429(6993): p. 771-6.

[175] Prozorovski, T., et al., Sirt1 contributes critically to the redox-dependent fate of neural progenitors. Nat Cell Biol, 2008. 10(4): p. 385-94.

[176] McBurney, M.W., et al., The mammalian SIR2alpha protein has a role in embryogenesis and gametogenesis. Mol Cell Biol, 2003. 23(1): p. 38-54.

[177] Dambacher, S., M. Hahn, and G. Schotta, Epigenetic regulation of development by histone lysine methylation. Heredity, 2010. 105(1): p. 24-37.

[178] Barski, A., et al., High-resolution profiling of histone methylations in the human genome. Cell, 2007. 129(4): p. 823-37.

[179] Cui, K., et al., Chromatin signatures in multipotent human hematopoietic stem cells indicate the fate of bivalent genes during differentiation. Cell Stem Cell, 2009. 4(1): p. 80-93.

[180] Pauler, F.M., et al., H3K27me3 forms BLOCs over silent genes and intergenic regions and specifies a histone banding pattern on a mouse autosomal chromosome. Genome Res, 2009. 19(2): p. 221-33.

[181] Yagi, H., et al., Growth disturbance in fetal liver hematopoiesis of Mll-mutant mice. Blood, 1998. 92(1): p. 108-17.

[182] Yu, B.D., et al., Altered Hox expression and segmental identity in Mll-mutant mice. Nature, 1995. 378(6556): p. 505-8.

[183] Ernst, P., et al., Definitive hematopoiesis requires the mixed-lineage leukemia gene. Dev Cell, 2004. 6(3): p. 437-43.

[184] Glaser, S., et al., Multiple epigenetic maintenance factors implicated by the loss of Mll2 in mouse development. Development, 2006. 133(8): p. 1423-32.

[185] Glaser, S., et al., The histone 3 lysine 4 methyltransferase, Mll2, is only required briefly in development and spermatogenesis. Epigenetics Chromatin, 2009. 2(1): p. 5.

[186] Lee, J., et al., Targeted inactivation of MLL3 histone H3-Lys-4 methyltransferase activity in the mouse reveals vital roles for MLL3 in adipogenesis. Proc Natl Acad Sci U S A, 2008. 105(49): p. 19229-34.

[187] Heuser, M., et al., Loss of MLL5 results in pleiotropic hematopoietic defects, reduced neutrophil immune function, and extreme sensitivity to DNA demethylation. Blood, 2009. 113(7): p. 1432-43.

[188] O'Carroll, D., et al., The polycomb-group gene Ezh2 is required for early mouse development. Mol Cell Biol, 2001. 21(13): p. 4330-6. 
[189] Ezhkova, E., et al., Ezh2 orchestrates gene expression for the stepwise differentiation of tissuespecific stem cells. Cell, 2009. 136(6): p. 1122-35.

[190] Margueron, R., et al., Ezh1 and Ezh2 maintain repressive chromatin through different mechanisms. Mol Cell, 2008. 32(4): p. 503-18.

[191] Su, I.H., et al., Ezh2 controls B cell development through histone H3 methylation and Igh rearrangement. Nat Immunol, 2003. 4(2): p. 124-31.

[192] Peters, A.H., et al., Loss of the Suv39h histone methyltransferases impairs mammalian heterochromatin and genome stability. Cell, 2001. 107(3): p. 323-37.

[193] Dodge, J.E., et al., Histone H3-K9 methyltransferase ESET is essential for early development. Mol Cell Biol, 2004. 24(6): p. 2478-86.

[194] Takada, I., et al., A histone lysine methyltransferase activated by non-canonical Wnt signalling suppresses PPAR-gamma transactivation. Nat Cell Biol, 2007. 9(11): p. 127385.

[195] Tachibana, M., et al., Histone methyltransferases G9a and GLP form heteromeric complexes and are both crucial for methylation of euchromatin at H3-K9. Genes Dev, 2005. 19(7): p. 815-26.

[196] Tachibana, M., et al., G9a histone methyltransferase plays a dominant role in euchromatic histone H3 lysine 9 methylation and is essential for early embryogenesis. Genes Dev, 2002. 16(14): p. 1779-91.

[197] Feldman, N., et al., G9a-mediated irreversible epigenetic inactivation of Oct-3/4 during early embryogenesis. Nat Cell Biol, 2006. 8(2): p. 188-94.

[198] Epsztejn-Litman, S., et al., De novo DNA methylation promoted by G9a prevents reprogramming of embryonically silenced genes. Nat Struct Mol Biol, 2008. 15(11): p. 1176-83.

[199] Wagschal, A., et al., G9a histone methyltransferase contributes to imprinting in the mouse placenta. Mol Cell Biol, 2008. 28(3): p. 1104-13.

[200] Pedersen, M.T. and K. Helin, Histone demethylases in development and disease. Trends Cell Biol, 2010. 20(11): p. 662-71.

[201] Shi, Y., Histone lysine demethylases: emerging roles in development, physiology and disease. Nat Rev Genet, 2007. 8(11): p. 829-33.

[202] Wang, J., et al., The lysine demethylase LSD1 (KDM1) is required for maintenance of global DNA methylation. Nat Genet, 2009. 41(1): p. 125-9.

[203] Ciccone, D.N., et al., KDM1B is a histone H3K4 demethylase required to establish maternal genomic imprints. Nature, 2009. 461(7262): p. 415-8.

[204] Fan, Z., et al., BCOR regulates mesenchymal stem cell function by epigenetic mechanisms. Nat Cell Biol, 2009. 11(8): p. 1002-9.

[205] Liu, Z., et al., Jmjd1a demethylase-regulated histone modification is essential for cAMPresponse element modulator-regulated gene expression and spermatogenesis. J Biol Chem, 2010. 285(4): p. 2758-70.

[206] Okada, Y., et al., Histone demethylase JHDM2A is critical for Tnp1 and Prm1 transcription and spermatogenesis. Nature, 2007. 450(7166): p. 119-23.

[207] Loh, Y.H., et al., Jmjd1a and Jmjd2c histone H3 Lys 9 demethylases regulate self-renewal in embryonic stem cells. Genes Dev, 2007. 21(20): p. 2545-57.

[208] Lopez-Bigas, N., et al., Genome-wide analysis of the H3K4 histone demethylase RBP2 reveals a transcriptional program controlling differentiation. Mol Cell, 2008. 31(4): p. 520-30. 
[209] Agger, K., et al., UTX and JMJD3 are histone H3K27 demethylases involved in HOX gene regulation and development. Nature, 2007. 449(7163): p. 731-4.

[210] Lan, F., et al., A histone H3 lysine 27 demethylase regulates animal posterior development. Nature, 2007. 449(7163): p. 689-94.

[211] Burgold, T., et al., The histone H3 lysine 27-specific demethylase Jmjd3 is required for neural commitment. PLoS One, 2008. 3(8): p. e3034.

[212] Jepsen, K., et al., SMRT-mediated repression of an H3K27 demethylase in progression from neural stem cell to neuron. Nature, 2007. 450(7168): p. 415-9.

[213] Sen, G.L., et al., Control of differentiation in a self-renewing mammalian tissue by the histone demethylase JMJD3. Genes Dev, 2008. 22(14): p. 1865-70.

[214] Huang, C., et al., Dual-specificity histone demethylase KIAA1718 (KDM7A) regulates neural differentiation through FGF4. Cell Res, 2010. 20(2): p. 154-65.

[215] Lan, J., et al., DNA methyltransferases and methyl-binding proteins of mammals. Acta Biochim Biophys Sin (Shanghai), 2010. 42(4): p. 243-52.

[216] Latham, T., N. Gilbert, and B. Ramsahoye, DNA methylation in mouse embryonic stem cells and development. Cell Tissue Res, 2008. 331(1): p. 31-55.

[217] Lei, H., et al., De novo DNA cytosine methyltransferase activities in mouse embryonic stem cells. Development, 1996. 122(10): p. 3195-205.

[218] Okano, M. and E. Li, Genetic analyses of DNA methyltransferase genes in mouse model system. J Nutr, 2002. 132(8 Suppl): p. 2462S-2465S.

[219] Okano, M., et al., DNA methyltransferases Dnmt3a and Dnmt3b are essential for de novo methylation and mammalian development. Cell, 1999. 99(3): p. 247-57.

[220] Watanabe, D., et al., Stage- and cell-specific expression of Dnmt3a and Dnmt3b during embryogenesis. Mech Dev, 2002. 118(1-2): p. 187-90.

[221] Watanabe, D., et al., Expression of Dnmt3b in mouse hematopoietic progenitor cells and spermatogonia at specific stages. Gene Expr Patterns, 2004. 5(1): p. 43-9.

[222] Watanabe, D., K. Uchiyama, and K. Hanaoka, Transition of mouse de novo methyltransferases expression from Dnmt3b to Dnmt3a during neural progenitor cell development. Neuroscience, 2006. 142(3): p. 727-37.

[223] Arima, T., et al., Loss of the maternal imprint in Dnmt3Lmat-/- mice leads to a differentiation defect in the extraembryonic tissue. Dev Biol, 2006. 297(2): p. 361-73.

[224] Webster, K.E., et al., Meiotic and epigenetic defects in Dnmt3L-knockout mouse spermatogenesis. Proc Natl Acad Sci U S A, 2005. 102(11): p. 4068-73.

[225] Hata, K., et al., Dnmt3L cooperates with the Dnmt3 family of de novo DNA methyltransferases to establish maternal imprints in mice. Development, 2002. 129(8): p. 1983-93.

[226] Kaneda, M., et al., Essential role for de novo DNA methyltransferase Dnmt3a in paternal and maternal imprinting. Nature, 2004. 429(6994): p. 900-3.

[227] Tsumura, A., et al., Maintenance of self-renewal ability of mouse embryonic stem cells in the absence of DNA methyltransferases Dnmt1, Dnmt3a and Dnmt3b. Genes Cells, 2006. 11(7): p. 805-14.

[228] Jackson, M., et al., Severe global DNA hypomethylation blocks differentiation and induces histone hyperacetylation in embryonic stem cells. Mol Cell Biol, 2004. 24(20): p. 8862-71.

[229] Saladi, S.V. and I.L. de la Serna, ATP dependent chromatin remodeling enzymes in embryonic stem cells. Stem Cell Rev, 2010. 6(1): p. 62-73. 
[230] de la Serna, I.L., Y. Ohkawa, and A.N. Imbalzano, Chromatin remodelling in mammalian differentiation: lessons from ATP-dependent remodellers. Nat Rev Genet, 2006. 7(6): p. 461-73.

[231] Moshkin, Y.M., et al., Functional differentiation of SWI/SNF remodelers in transcription and cell cycle control. Mol Cell Biol, 2007. 27(2): p. 651-61.

[232] Bultman, S., et al., A Brg1 null mutation in the mouse reveals functional differences among mammalian SWI/SNF complexes. Mol Cell, 2000. 6(6): p. 1287-95.

[233] Guidi, C.J., et al., Disruption of Ini1 leads to peri-implantation lethality and tumorigenesis in mice. Mol Cell Biol, 2001. 21(10): p. 3598-603.

[234] Lickert, H., et al., Baf60c is essential for function of BAF chromatin remodelling complexes in heart development. Nature, 2004. 432(7013): p. 107-12.

[235] Wang, Z., et al., Polybromo protein BAF180 functions in mammalian cardiac chamber maturation. Genes Dev, 2004. 18(24): p. 3106-16.

[236] Kim, J.K., et al., Srg3, a mouse homolog of yeast SWI3, is essential for early embryogenesis and involved in brain development. Mol Cell Biol, 2001. 21(22): p. 7787-95.

[237] Ho, L., et al., An embryonic stem cell chromatin remodeling complex, esBAF, is essential for embryonic stem cell self-renewal and pluripotency. Proc Natl Acad Sci U S A, 2009. 106(13): p. 5181-6.

[238] Yan, Z., et al., BAF250B-associated SWI/SNF chromatin-remodeling complex is required to maintain undifferentiated mouse embryonic stem cells. Stem Cells, 2008. 26(5): p. 115565.

[239] Gao, X., et al., ES cell pluripotency and germ-layer formation require the SWI/SNF chromatin remodeling component BAF250a. Proc Natl Acad Sci U S A, 2008. 105(18): p. 6656-61.

[240] Schaniel, C., et al., Smarcc1/Baf155 couples self-renewal gene repression with changes in chromatin structure in mouse embryonic stem cells. Stem Cells, 2009. 27(12): p. 2979-91.

[241] Stopka, T. and A.I. Skoultchi, The ISWI ATPase Snf2h is required for early mouse development. Proc Natl Acad Sci U S A, 2003. 100(24): p. 14097-102.

[242] Banting, G.S., et al., CECR2, a protein involved in neurulation, forms a novel chromatin remodeling complex with SNF2L. Hum Mol Genet, 2005. 14(4): p. 513-24.

[243] Barak, O., et al., Isolation of human NURF: a regulator of Engrailed gene expression. EMBO J, 2003. 22(22): p. 6089-100.

[244] Landry, J., et al., Essential role of chromatin remodeling protein Bptf in early mouse embryos and embryonic stem cells. PLoS Genet, 2008. 4(10): p. e1000241.

[245] Gaspar-Maia, A., et al., Chd1 regulates open chromatin and pluripotency of embryonic stem cells. Nature, 2009. 460(7257): p. 863-8.

[246] Bosman, E.A., et al., Multiple mutations in mouse Chd7 provide models for CHARGE syndrome. Hum Mol Genet, 2005. 14(22): p. 3463-76.

[247] Pouponnot, C., L. Jayaraman, and J. Massague, Physical and functional interaction of SMADs and p300/CBP. J Biol Chem, 1998. 273(36): p. 22865-8.

[248] Itoh, S., et al., The transcriptional co-activator P/CAF potentiates TGF-beta/Smad signaling. Nucleic Acids Res, 2000. 28(21): p. 4291-8.

[249] Kahata, K., et al., Regulation of transforming growth factor-beta and bone morphogenetic protein signalling by transcriptional coactivator GCN5. Genes Cells, 2004. 9(2): p. 14351.

[250] Frontelo, P., et al., Suv39h histone methyltransferases interact with Smads and cooperate in BMP-induced repression. Oncogene, 2004. 23(30): p. 5242-51. 
[251] Gronroos, E., et al., Control of Smad7 stability by competition between acetylation and ubiquitination. Mol Cell, 2002. 10(3): p. 483-93.

[252] Bai, S. and X. Cao, A nuclear antagonistic mechanism of inhibitory Smads in transforming growth factor-beta signaling. J Biol Chem, 2002. 277(6): p. 4176-82.

[253] Lin, X., et al., Smad6 recruits transcription corepressor CtBP to repress bone morphogenetic protein-induced transcription. Mol Cell Biol, 2003. 23(24): p. 9081-93.

[254] Wu, K., et al., DACH1 inhibits transforming growth factor-beta signaling through binding Smad4. J Biol Chem, 2003. 278(51): p. 51673-84.

[255] Kida, Y., et al., Chick Dach1 interacts with the Smad complex and Sin3a to control AER formation and limb development along the proximodistal axis. Development, 2004. 131(17): p. 4179-87.

[256] Luo, K., et al., The Ski oncoprotein interacts with the Smad proteins to repress TGFbeta signaling. Genes Dev, 1999. 13(17): p. 2196-206.

[257] Akiyoshi, S., et al., c-Ski acts as a transcriptional co-repressor in transforming growth factorbeta signaling through interaction with smads. J Biol Chem, 1999. 274(49): p. 35269-77.

[258] Melhuish, T.A., C.M. Gallo, and D. Wotton, TGIF2 interacts with histone deacetylase 1 and represses transcription. J Biol Chem, 2001. 276(34): p. 32109-14.

[259] Hecht, A., et al., The p300/CBP acetyltransferases function as transcriptional coactivators of beta-catenin in vertebrates. EMBO J, 2000. 19(8): p. 1839-50.

[260] Takemaru, K.I. and R.T. Moon, The transcriptional coactivator CBP interacts with betacatenin to activate gene expression. J Cell Biol, 2000. 149(2): p. 249-54.

[261] Sierra, J., et al., The APC tumor suppressor counteracts beta-catenin activation and H3K4 methylation at Wnt target genes. Genes Dev, 2006. 20(5): p. 586-600.

[262] Janknecht, R. and A. Nordheim, MAP kinase-dependent transcriptional coactivation by Elk1 and its cofactor CBP. Biochem Biophys Res Commun, 1996. 228(3): p. 831-7.

[263] Kretzschmar, M., J. Doody, and J. Massague, Opposing BMP and EGF signalling pathways converge on the TGF-beta family mediator Smad1. Nature, 1997. 389(6651): p. 618-22.

[264] Kretzschmar, M., et al., A mechanism of repression of TGFbeta/ Smad signaling by oncogenic Ras. Genes Dev, 1999. 13(7): p. 804-16.

[265] Roelen, B.A., et al., Phosphorylation of threonine 276 in Smad4 is involved in transforming growth factor-beta-induced nuclear accumulation. Am J Physiol Cell Physiol, 2003. 285(4): p. C823-30.

[266] Sif, S., et al., Mitotic inactivation of a human SWI/SNF chromatin remodeling complex. Genes Dev, 1998. 12(18): p. 2842-51.

[267] Foster, K.S., et al., Members of the hSWI/SNF chromatin remodeling complex associate with and are phosphorylated by protein kinase B/Akt. Oncogene, 2006. 25(33): p. 4605-12.

[268] Gao, H., et al., Akt/PKB interacts with the histone H3 methyltransferase SETDB1 and coordinates to silence gene expression. Mol Cell Biochem, 2007. 305(1-2): p. 35-44.

[269] Cha, T.L., et al., Akt-mediated phosphorylation of EZH2 suppresses methylation of lysine 27 in histone H3. Science, 2005. 310(5746): p. 306-10.

[270] Huang, W.C. and C.C. Chen, Akt phosphorylation of p300 at Ser-1834 is essential for its histone acetyltransferase and transcriptional activity. Mol Cell Biol, 2005. 25(15): p. 6592-602.

[271] Pardo, M., et al., An expanded Oct4 interaction network: implications for stem cell biology, development, and disease. Cell Stem Cell, 2010. 6(4): p. 382-95. 
[272] Dow, L.E. and P.O. Humbert, Polarity regulators and the control of epithelial architecture, cell migration, and tumorigenesis. Int Rev Cytol, 2007. 262: p. 253-302.

[273] Alarcon, V.B., Cell polarity regulator PARD6B is essential for trophectoderm formation in the preimplantation mouse embryo. Biol Reprod, 2010. 83(3): p. 347-58.

[274] Plusa, B., et al., Downregulation of Par3 and aPKC function directs cells towards the ICM in the preimplantation mouse embryo. J Cell Sci, 2005. 118(Pt 3): p. 505-15.

[275] Suzuki, A., et al., Nanog binds to Smad1 and blocks bone morphogenetic protein-induced differentiation of embryonic stem cells. Proc Natl Acad Sci U S A, 2006. 103(27): p. 10294-9. 


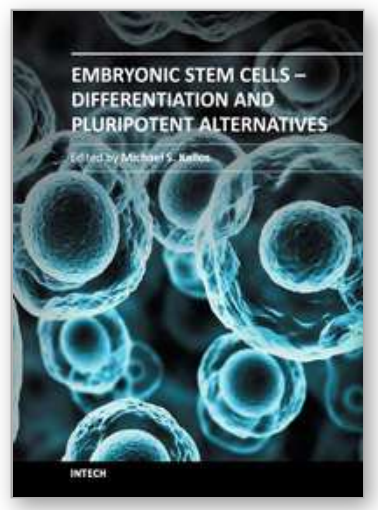

\author{
Embryonic Stem Cells - Differentiation and Pluripotent Alternatives \\ Edited by Prof. Michael S. Kallos
}

ISBN 978-953-307-632-4

Hard cover, 506 pages

Publisher InTech

Published online 12, October, 2011

Published in print edition October, 2011

The ultimate clinical implementation of embryonic stem cells will require methods and protocols to turn these unspecialized cells into the fully functioning cell types found in a wide variety of tissues and organs. In order to achieve this, it is necessary to clearly understand the signals and cues that direct embryonic stem cell differentiation. This book provides a snapshot of current research on the differentiation of embryonic stem cells to a wide variety of cell types, including neural, cardiac, endothelial, osteogenic, and hepatic cells. In addition, induced pluripotent stem cells and other pluripotent stem cell sources are described. The book will serve as a valuable resource for engineers, scientists, and clinicians as well as students in a wide range of disciplines.

\title{
How to reference
}

In order to correctly reference this scholarly work, feel free to copy and paste the following:

Prasenjit Sarkar and Balaji M. Rao (2011). Role of Signaling Pathways and Epigenetic Factors in Lineage Determination During Human Embryonic Stem Cell Differentiation, Embryonic Stem Cells - Differentiation and Pluripotent Alternatives, Prof. Michael S. Kallos (Ed.), ISBN: 978-953-307-632-4, InTech, Available from: http://www.intechopen.com/books/embryonic-stem-cells-differentiation-and-pluripotent-alternatives/role-ofsignaling-pathways-and-epigenetic-factors-in-lineage-determination-during-human-embryonic-st

\section{INTECH}

open science | open minds

\section{InTech Europe}

University Campus STeP Ri

Slavka Krautzeka 83/A

51000 Rijeka, Croatia

Phone: +385 (51) 770447

Fax: +385 (51) 686166

www.intechopen.com

\author{
InTech China \\ Unit 405, Office Block, Hotel Equatorial Shanghai \\ No.65, Yan An Road (West), Shanghai, 200040, China \\ 中国上海市延安西路65号上海国际贵都大饭店办公楼405单元 \\ Phone: +86-21-62489820 \\ Fax: $+86-21-62489821$
}


(C) 2011 The Author(s). Licensee IntechOpen. This is an open access article distributed under the terms of the Creative Commons Attribution 3.0 License, which permits unrestricted use, distribution, and reproduction in any medium, provided the original work is properly cited. 